Journal of Engineering Sciences, Assiut University, Vol. 35, No. 3 pp. 835-851, May 2007.

\title{
ARCHITECTURAL SPACE FROM MODERNISM TO DECONSTRUCTION: A CRITICAL OVERVIEW
}

\author{
Nouby Mohamed Hassan \\ Associate professor Department of Architecture and building science \\ College of Architecture, King Saud University \\ E-mail:nouby3000@yahoo.com
}

(Received April 3 ,2007 Accepted May,3 , 2007)

\begin{abstract}
The research dilemma of this paper lies in the arguable differences on the directions of deconstruction theory in architecture. The primary inquiry of this study focuses on these differences in addition to identifying the contributions of deconstruction on architectural spaces. However difficult, the paper provides an attempt through a comparison between the architectural theories of modernism and deconstruction (represented by Mies Van Der Rohe and Frank Owen Gehry respectively), in terms of thoughts and works in relation to architectural spaces.

The research methodology adopts a critical view by conducting a comparative analysis study for architectural spaces in modernism and deconstruction. Some of the important results of this study include asserting that architectural spaces are principally different in deconstruction compared to modernism in their boundaries, status, and the architectural character of buildings enclosing these spaces. The substantial change of the architectural spaces in deconstruction has come out through the variances of space boundaries, their architectural status internally and externally, and examining new shapes that are not bounded to familiar rules. This is in addition to stimulating the observer's view and attracting the attention while navigating the space wherein exquisite and natural views are utilized.
\end{abstract}

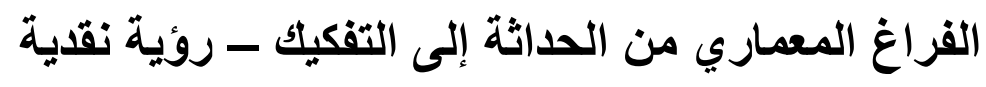

تظهر إثكالية هذا البحث في جدلية الخلاف القائم حول توجهات عمـارة التفكيك، و السؤال الرئيسي الذي يدور

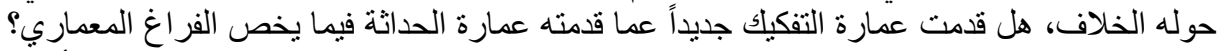

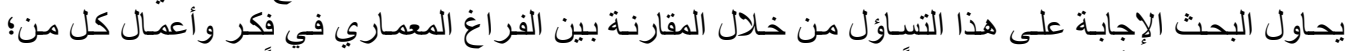

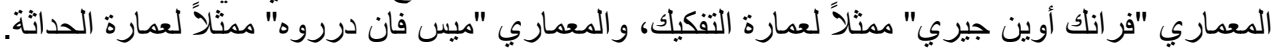

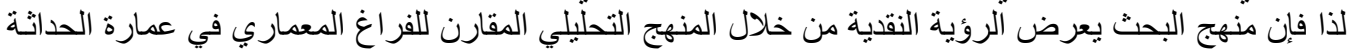
و عمارة التفكيك. الك.

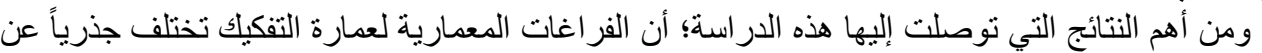

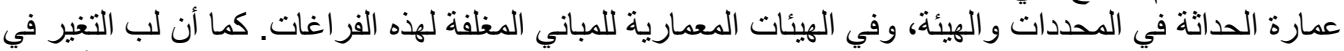

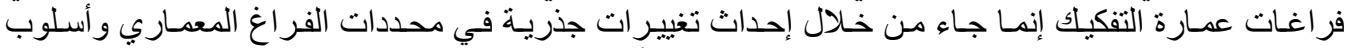

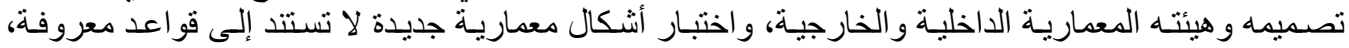




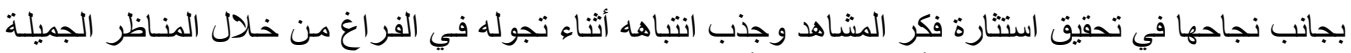
و المتغيرة التي يمكنه مشاهدتها، وكأنما تحقيق، وبأسلوب مختلف، لفكرة العلاقة بين الفراغ اغ و الزمن.

\section{1- ماهية الفراغ المعماري، ومحدداته}

جدير في هذا الجزء المختصر ، و الذي يعده البحث مقدمة للموضوع، أن نقدم فكرة عن الفراغ المعاع المعاري

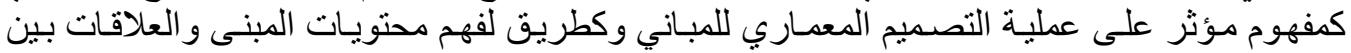

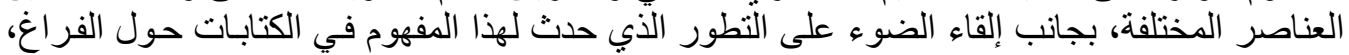

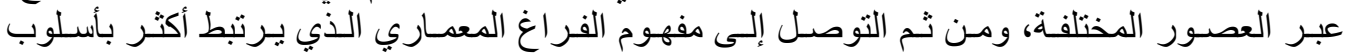

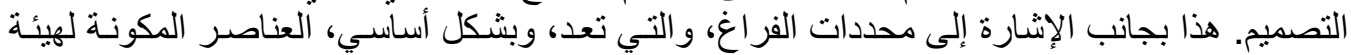

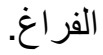

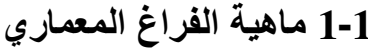

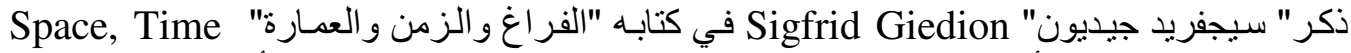
and Architecture

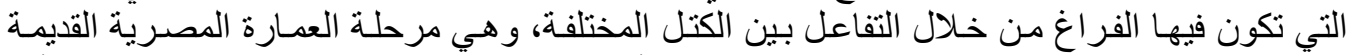

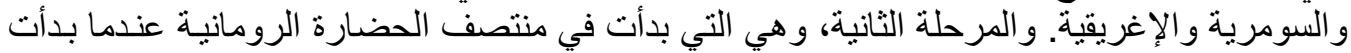

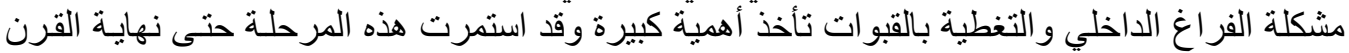

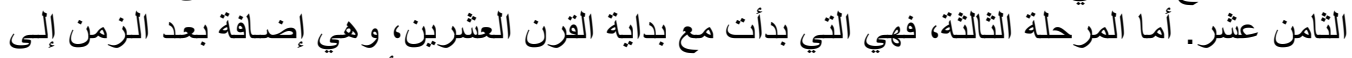

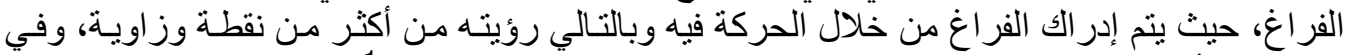

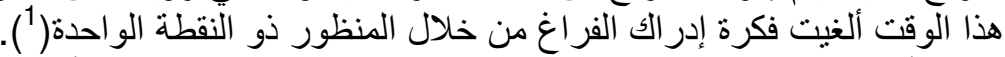

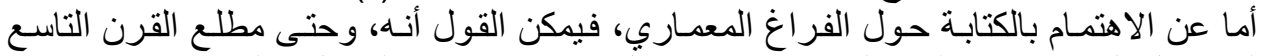

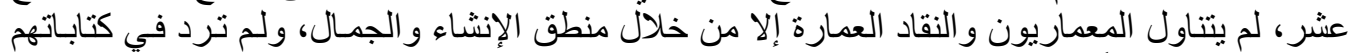

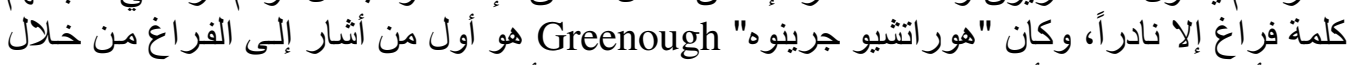

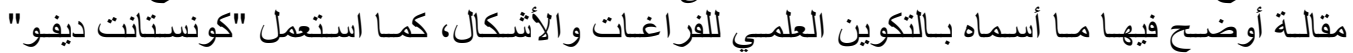
وكائ Constant Defoux

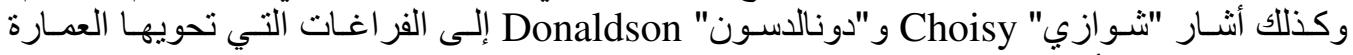

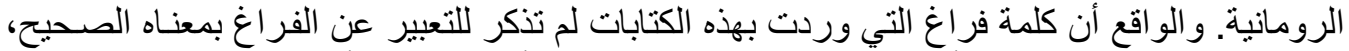

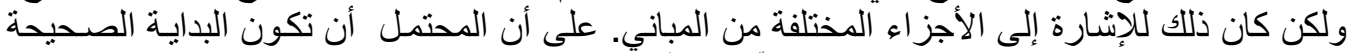

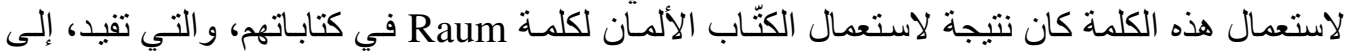

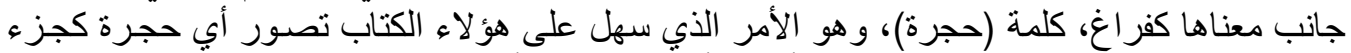

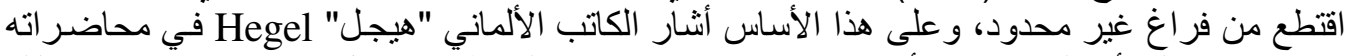

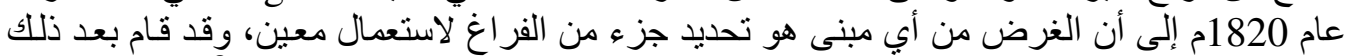

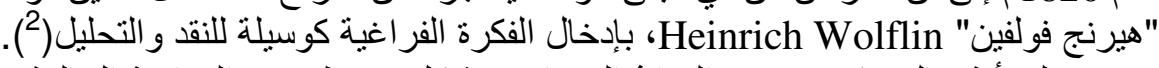

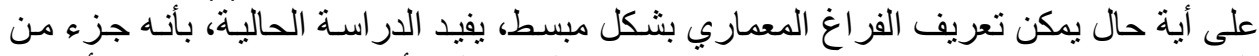

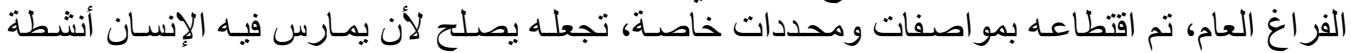

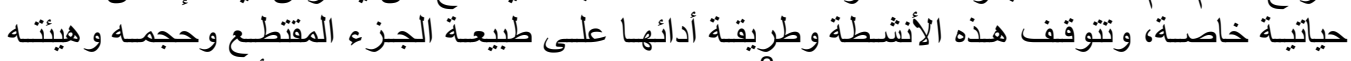

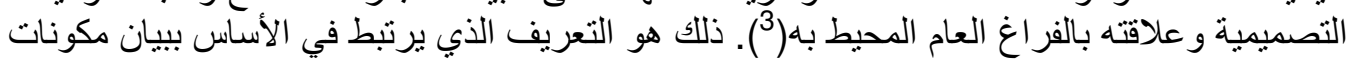

Giedion, S.(1967). Space, Time and Architecture. $\left({ }^{1}\right)$

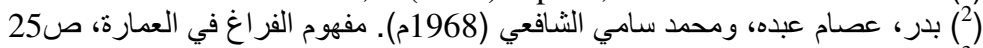

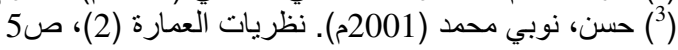




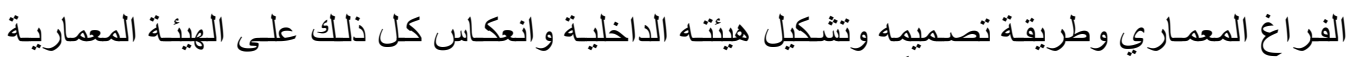

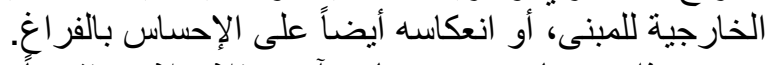

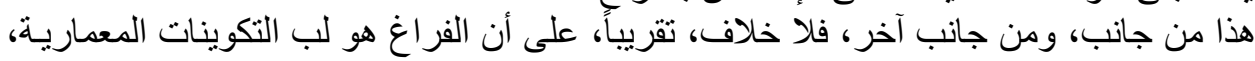

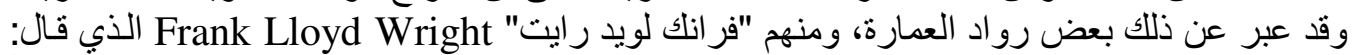

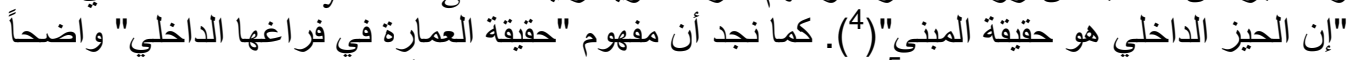

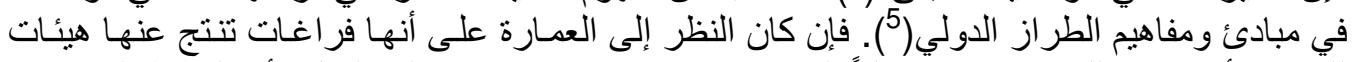

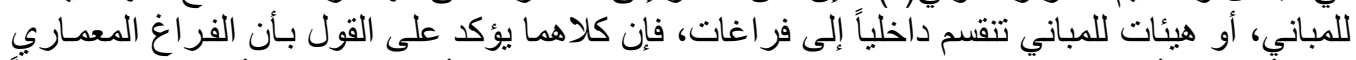

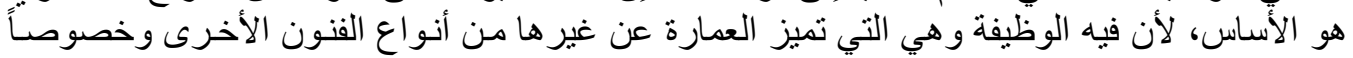
فن النحت.

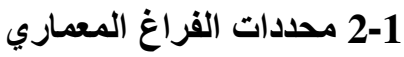

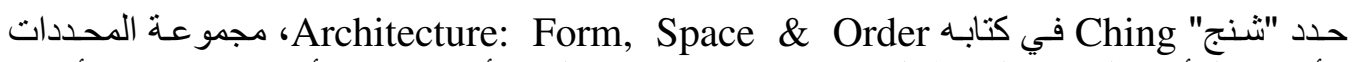

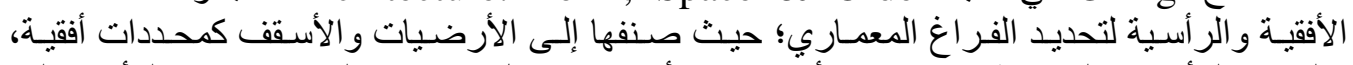

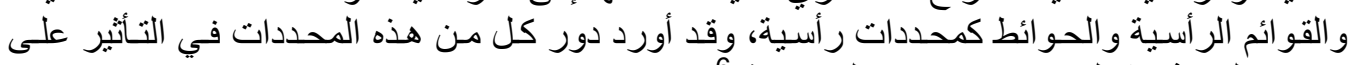

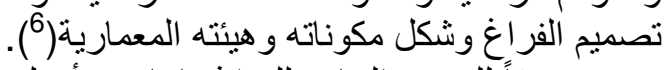

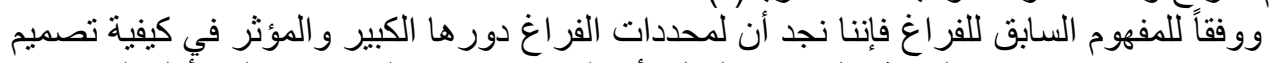

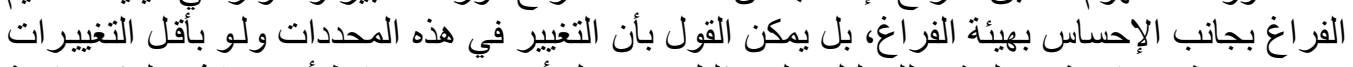

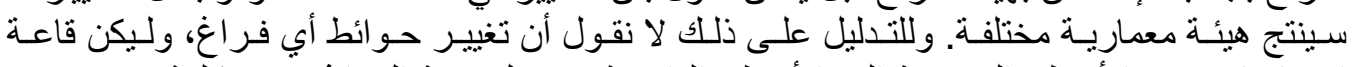

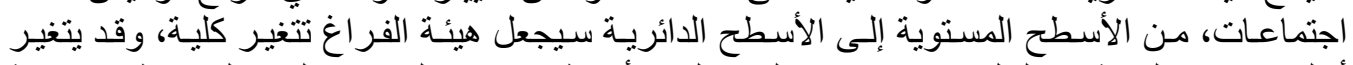

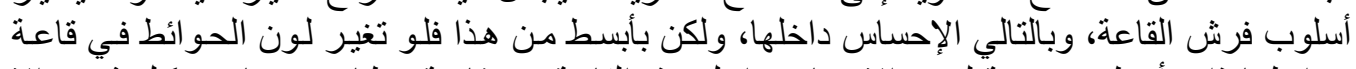

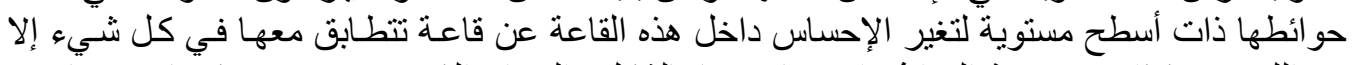

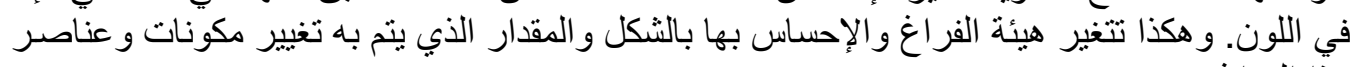
هذًا الفراغ.

\section{2- الدراسات السابقة في مجال البحث، الإثكالية والأهداف، ومنهجية الدراسة 1-2 الدراسات السابقة في مجال البحث}

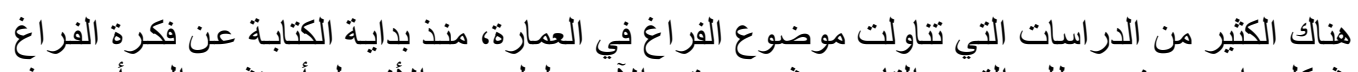

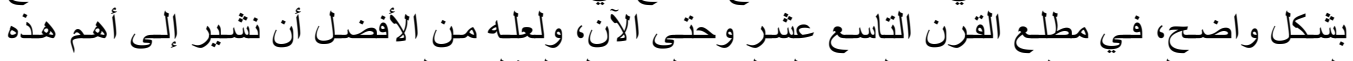

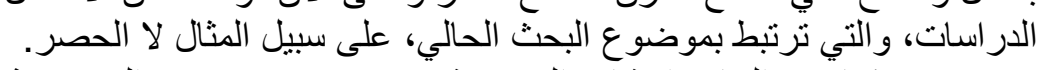

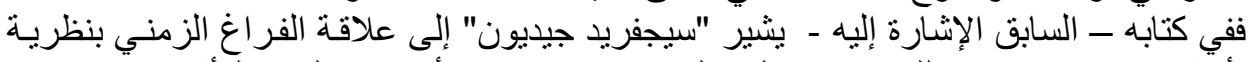

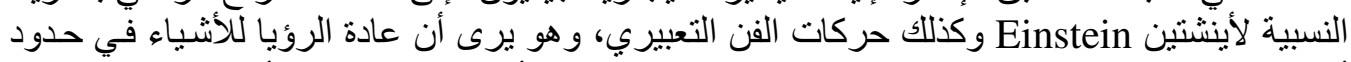

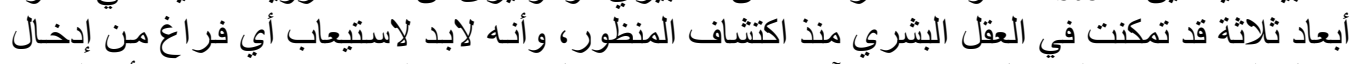

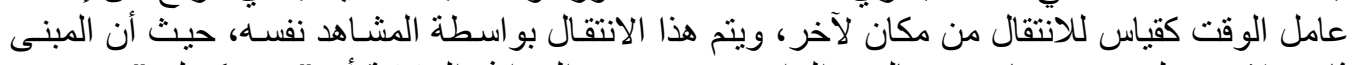

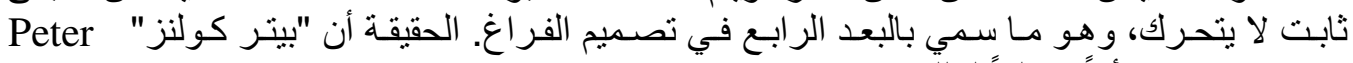

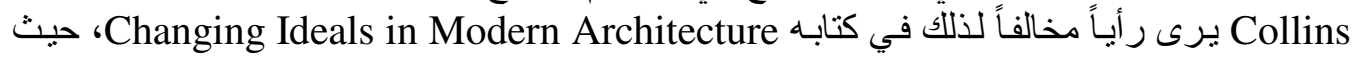

Kaufmann, E. \& Ben Raeburn. (1960). Frank Lloyd Wright, Writings \& Buildings, ( ${ }^{5}$ ) p. 284

(6) علي، خالد علي يوسف (2801م). العمارة المعاصرة و المردود الفكري و التطبيقي على العمارة المصرية المعاصرة (در اسة تحليلية).

Ching, F. D. K.(1979). Architecture: Form, Space \& Order, pp. 107- $174\left({ }^{4}\right)$ 


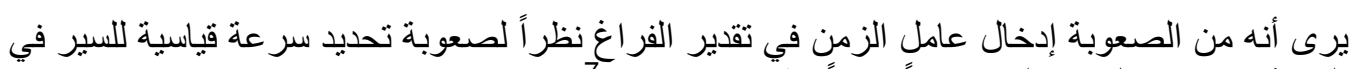

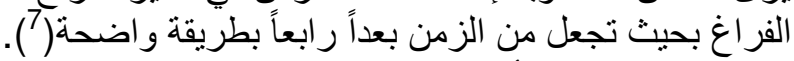

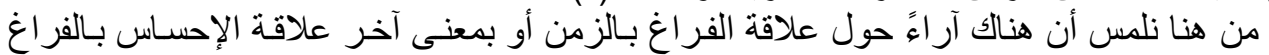

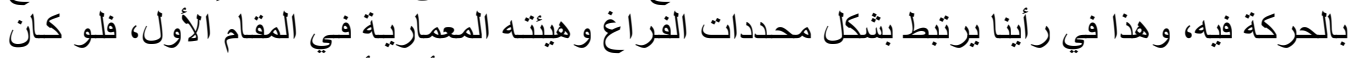

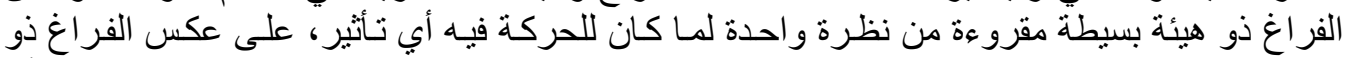

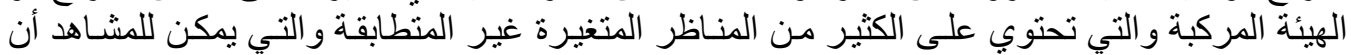
يدركها ويستمتع بها.

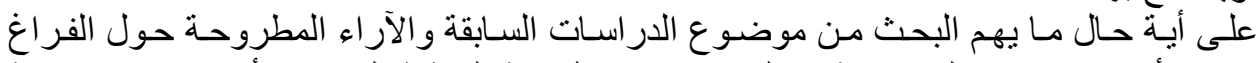

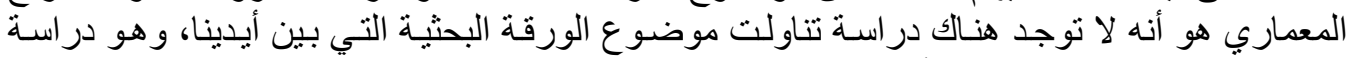

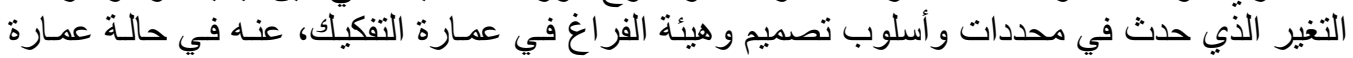

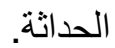

\section{2-2 2-2 إثكالية البحث وأهدافه}

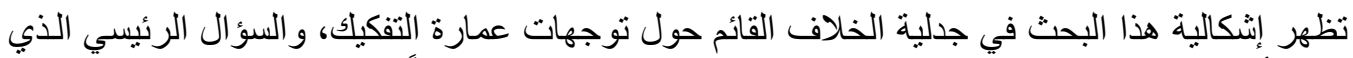

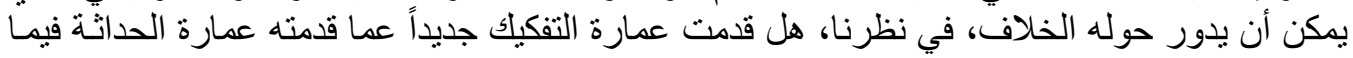

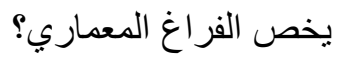
وحتى يمكن للبحث الإجابة على هذا السؤ ال فإنه قد حدد مجمو عة من الأهداف وأل وهي:

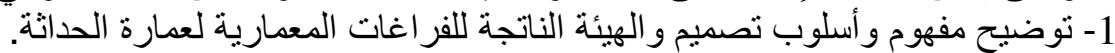

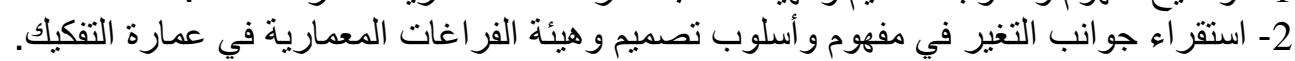

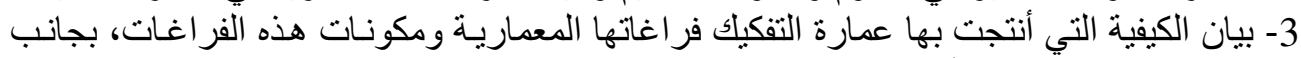

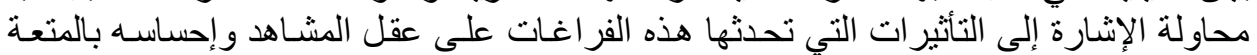

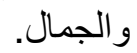

\section{ف 3-2 منهجية الدراسة}

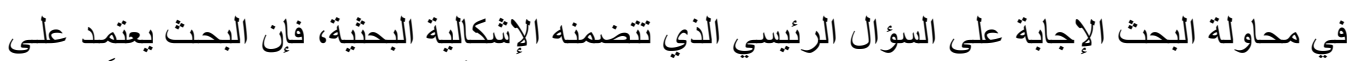

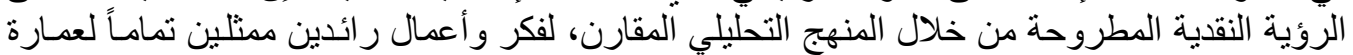

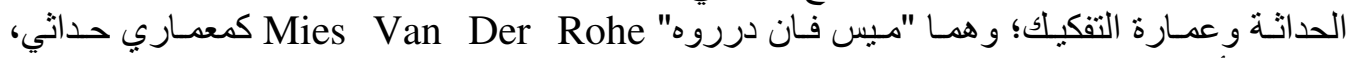
و "فر انك أوين جيري" Frank Owen Gehry كمعماري تفري تفكيكي.

\section{3- الروئة النقدية: الفراغ المعماري من الحداثة إلى التفكيك 1-3 لماذا عمارة الحداثة وعمارة التفكيك؟ الته}

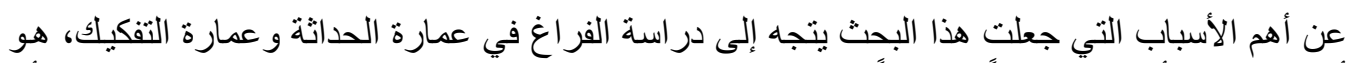

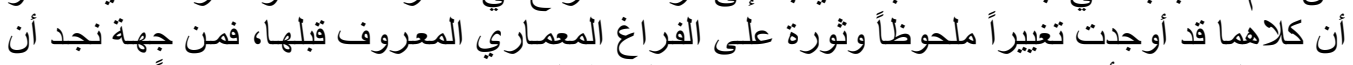

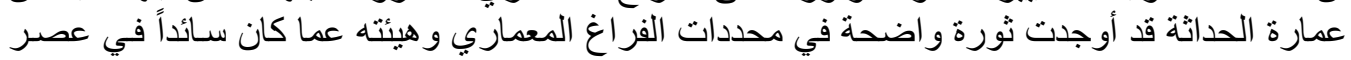

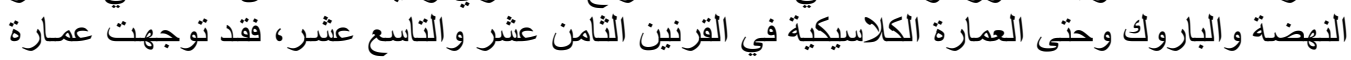

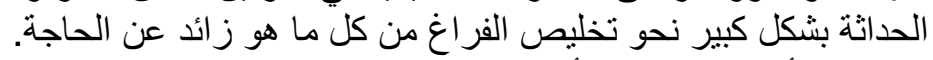

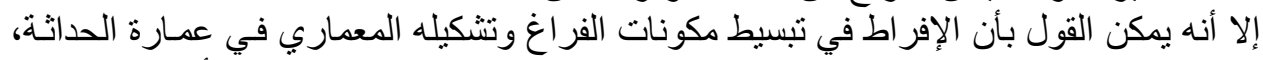

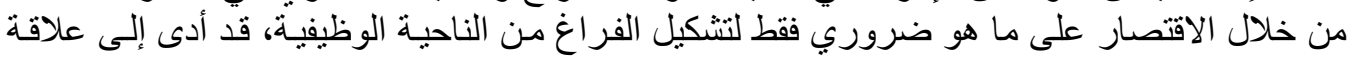

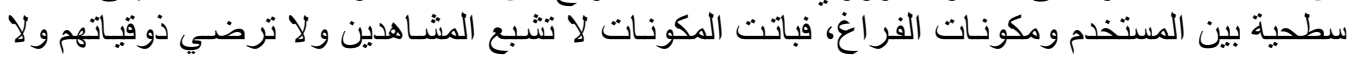

(7) بدر، عصام عبده، ومحمد سامي الثافعي (1968م). مفهوم الفراغ في العمارة، ص ص، 23، 24 


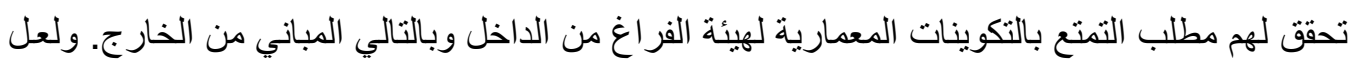

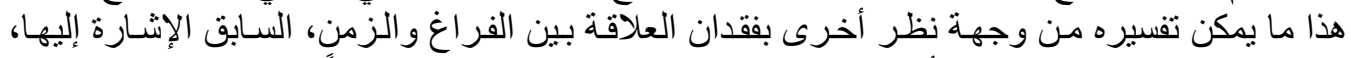

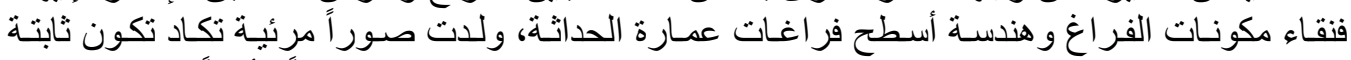

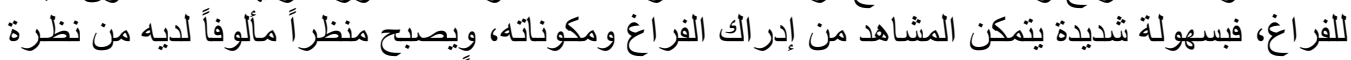

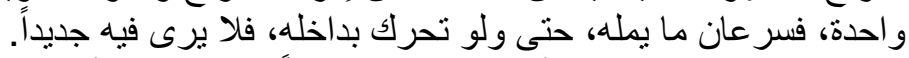

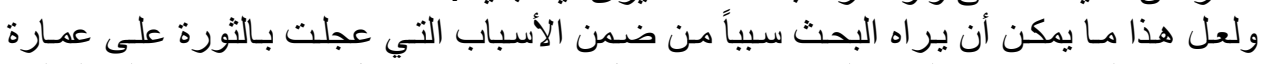

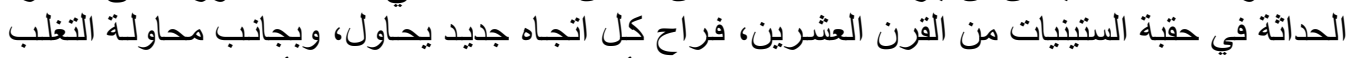

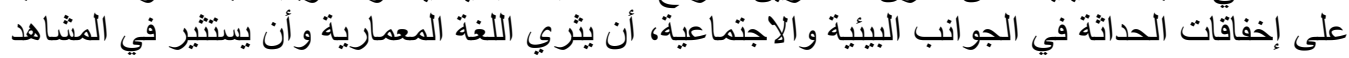
القيم الحسية و الروحية.

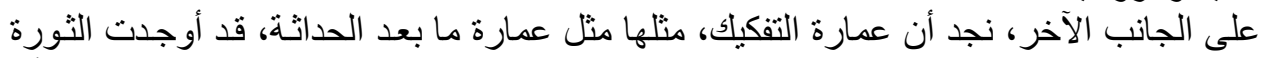

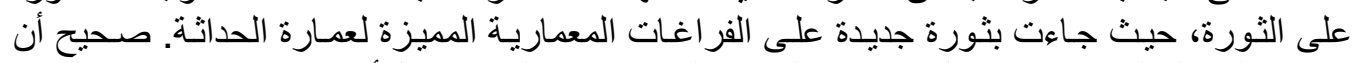

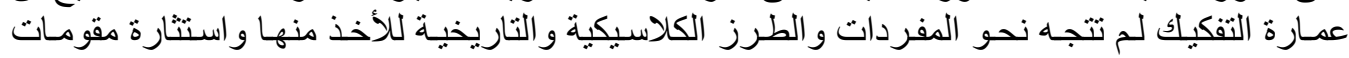

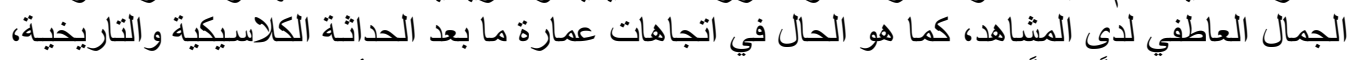

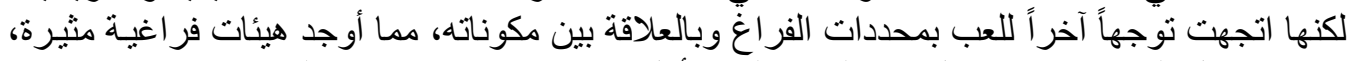

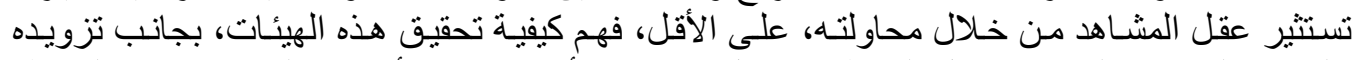

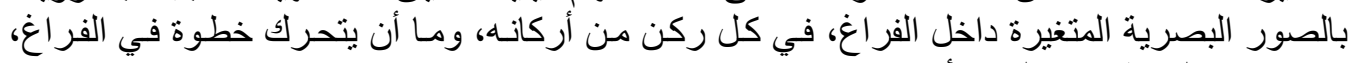
حتى تتغير المناظر وتختلف الئلف الأحاسيس.

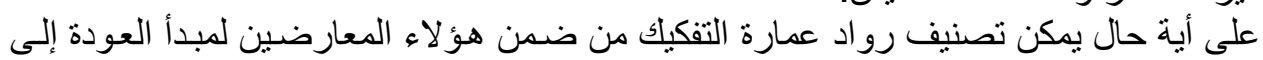

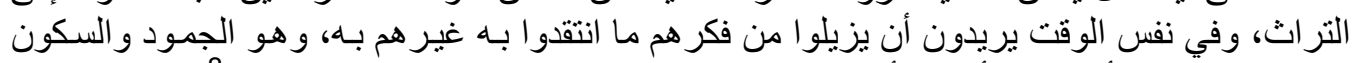

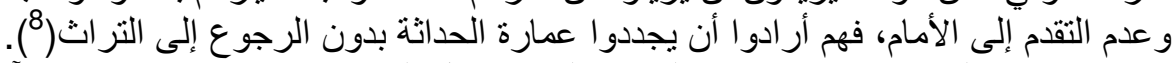

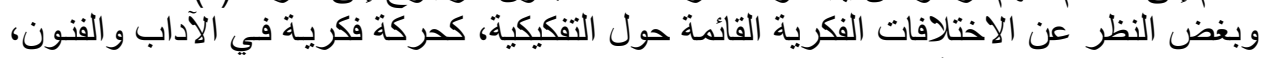

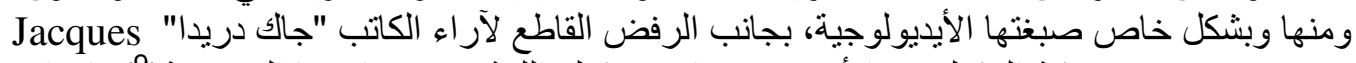

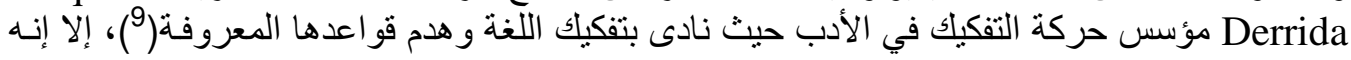

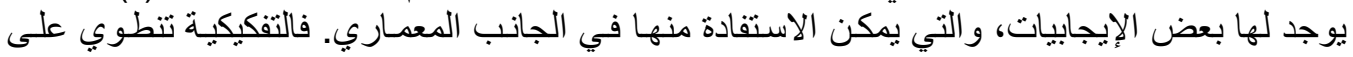

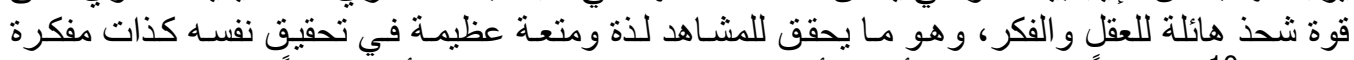

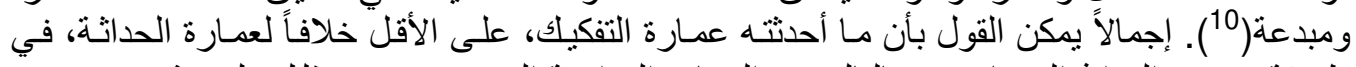

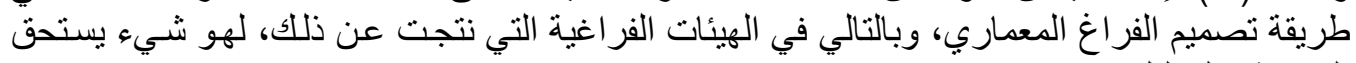

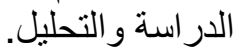

2-3 الحالة الاراسية: فكر وأعمال ميس فان درروه وفرانك أوين جيري

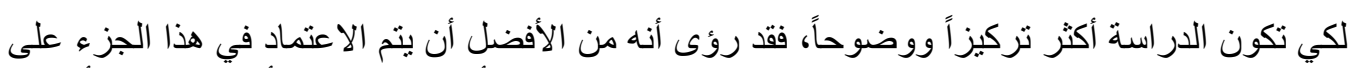

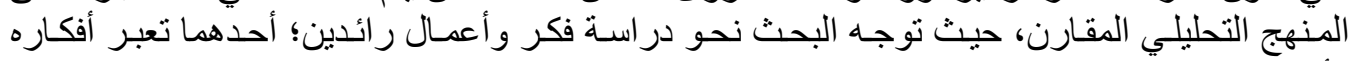

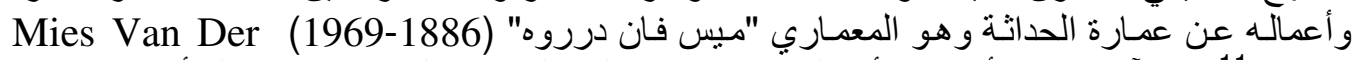
Rohe

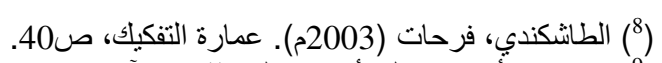

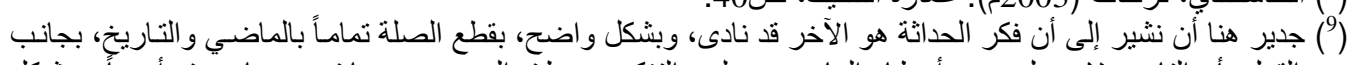

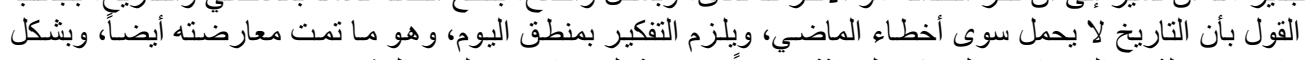

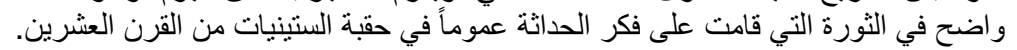

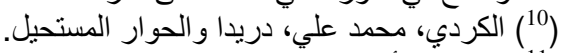

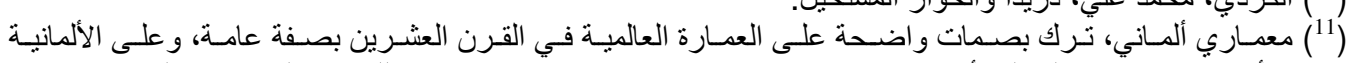

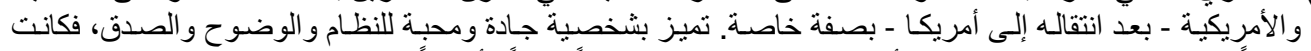

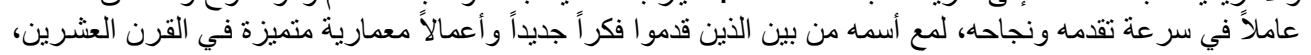




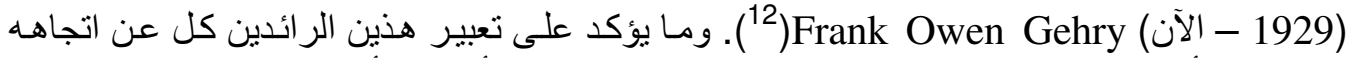

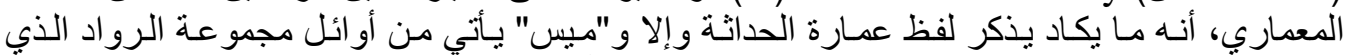

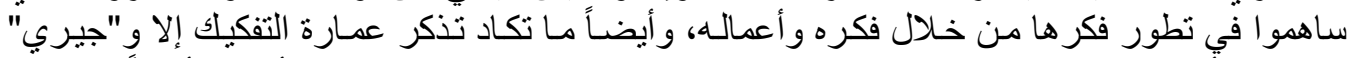

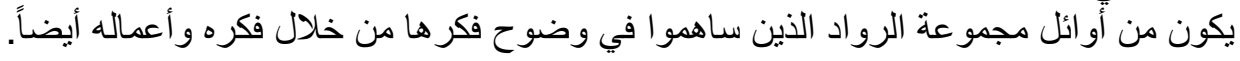

\section{1-2-3 الفراغ المعماري في فكر ميس وجيري}

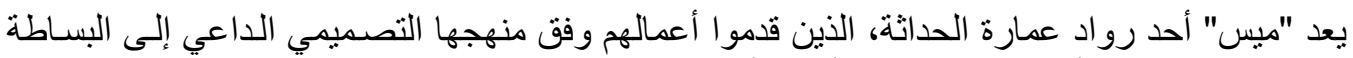

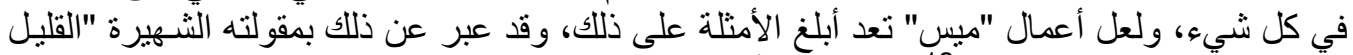

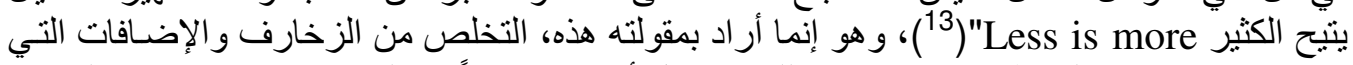

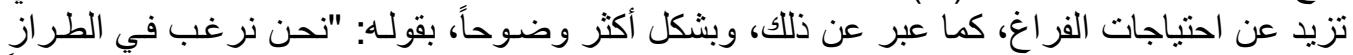

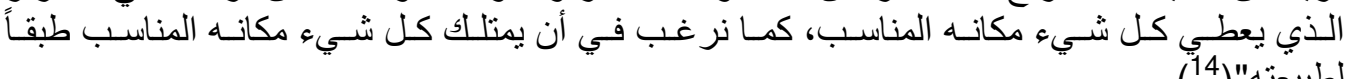
لطبيعته"(14).

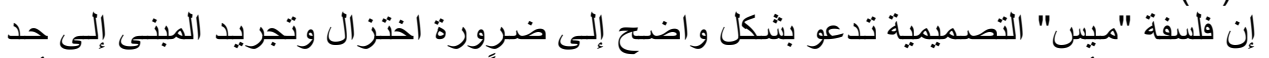

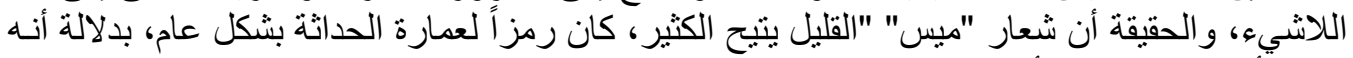

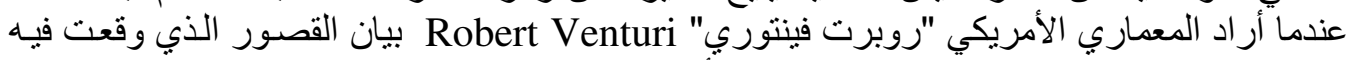

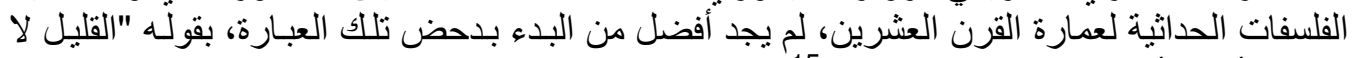

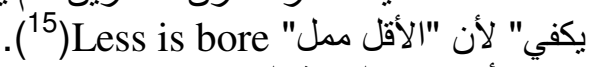

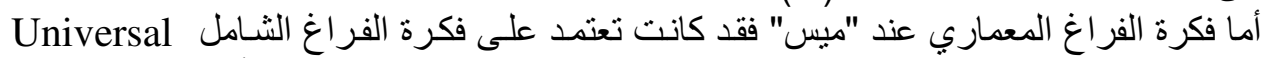

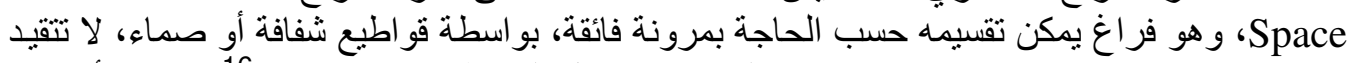

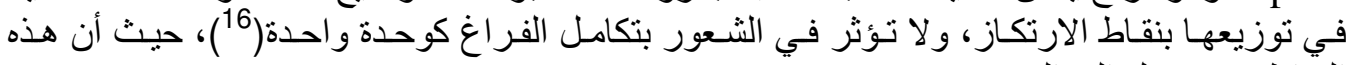

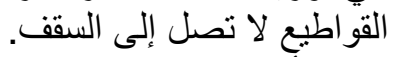

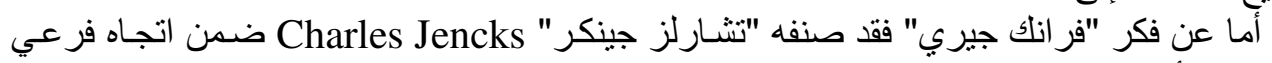

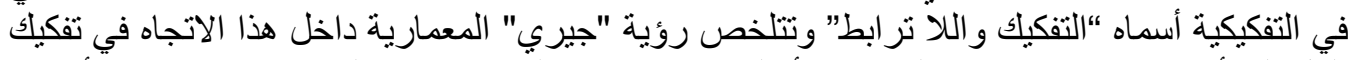

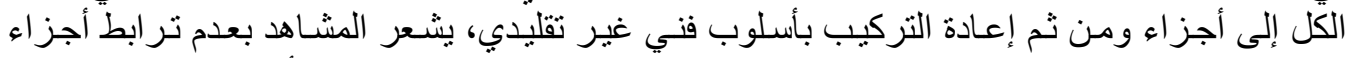

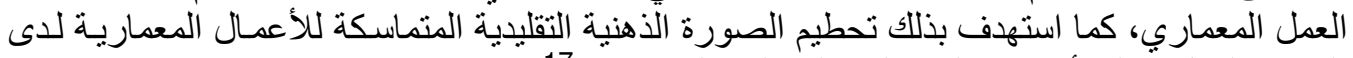

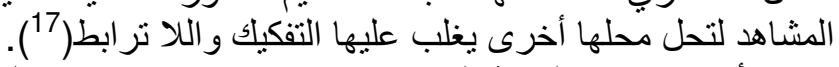

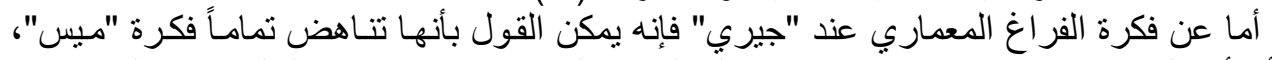

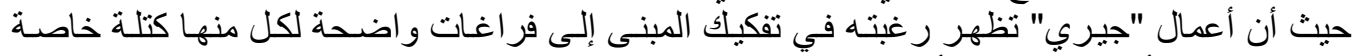
تميزها، وقد لجأ في كثير من الأحيان إلى تمييز الكتل عن بعضها بشكل و اضح ومستقل.

مما جعل البعض يعتبره من رواد الجيل الأول الذين ساهموا في تقدم العمارة وإعطاء سمة واضحة للعمارة الحديثة في

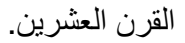

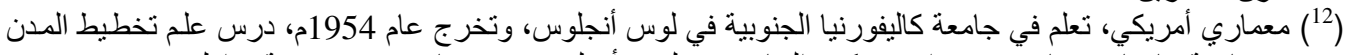

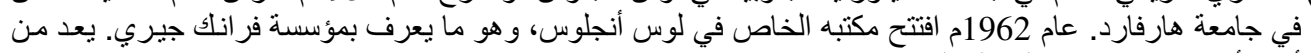
أهم و أشهر رواد عمارة التفكيك المعاصرين.

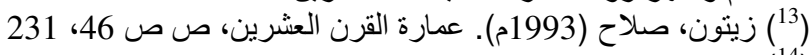
Giedion, S. (1967). Space, Time and Architecture , p.616 $\left({ }^{14}\right)$ (15)

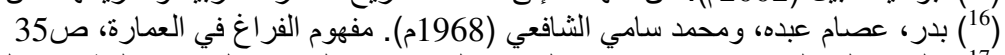

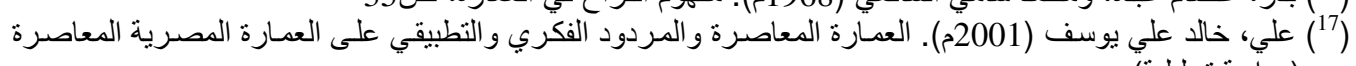
(دراسة تحليلية). 
2-2-3 نقد الفراغ المعماري في أعمال ميس وجيري

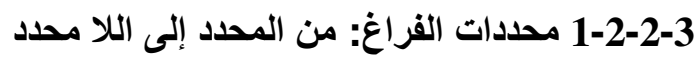

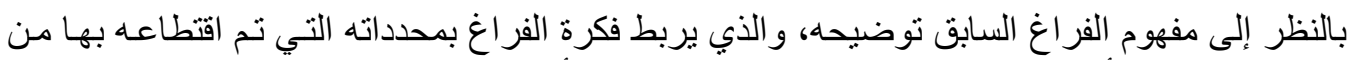

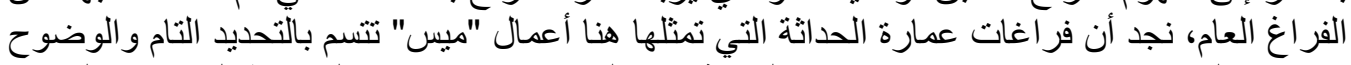

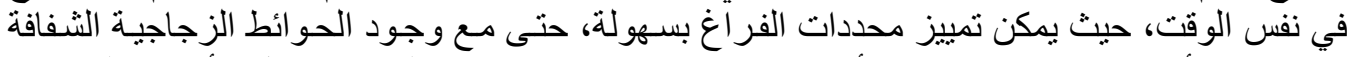

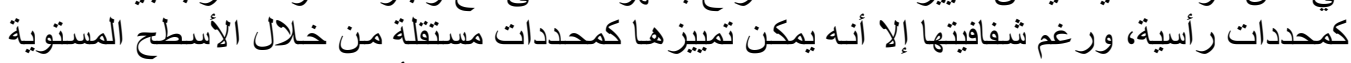

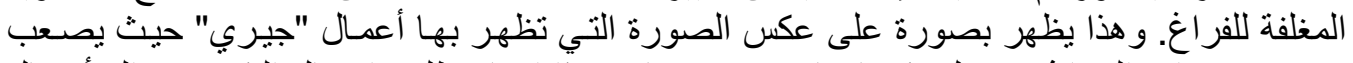

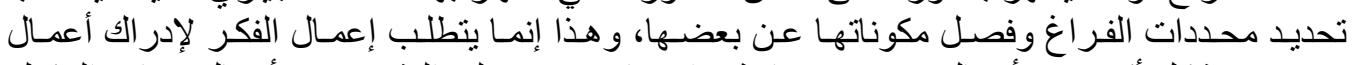

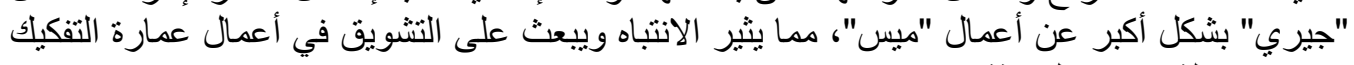
عنها في حالة عمارة الحداثة.

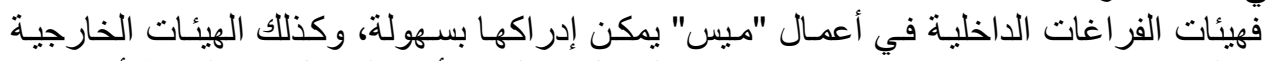

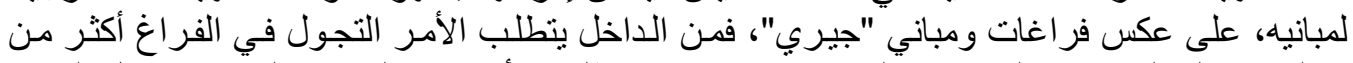

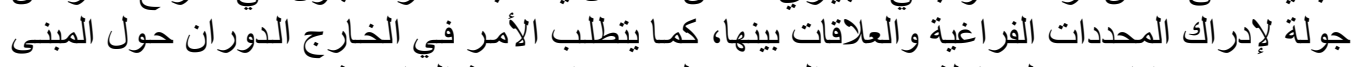

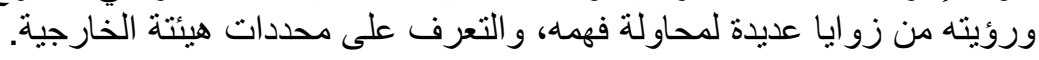

\section{2-2-2-3 تصميم الفراغ: من النظام إلى اللا نظام}

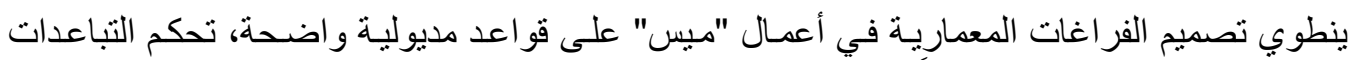

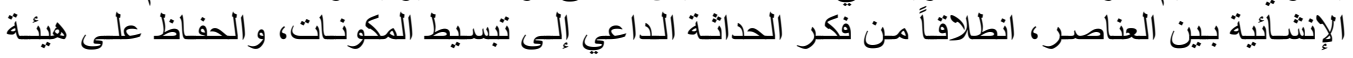

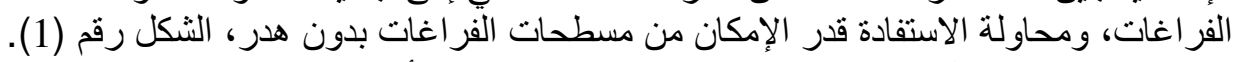

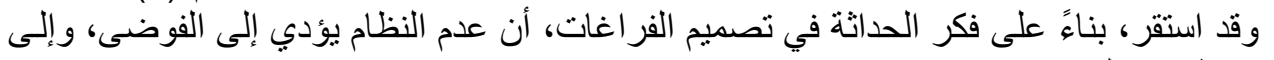
ضياع مسطحات الفر اغات بدون استخدام مدروس.

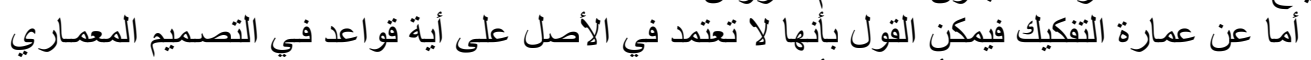

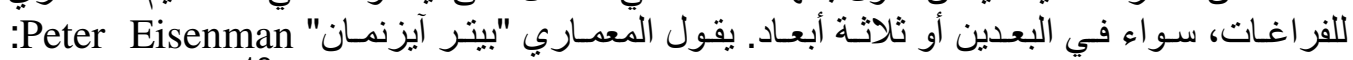

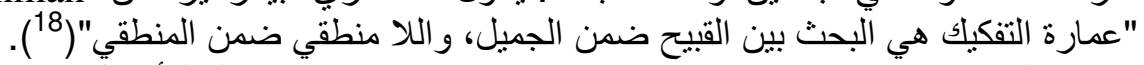

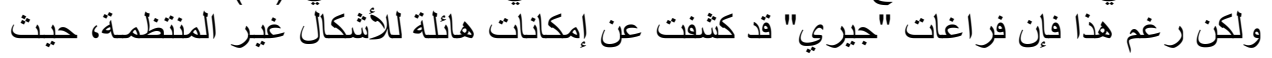
أنه يمكن بها تحقيق هيئات فر اغية مثيرة ورجذابة بالنسبة للمشاهد.

\section{3-2-2-3 هيئة الفراغ: من الهندية إلى اللا هندسية}

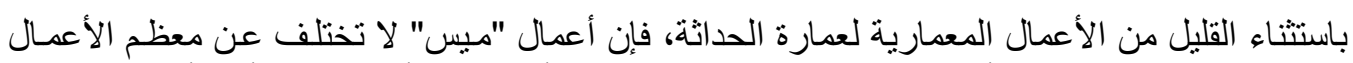

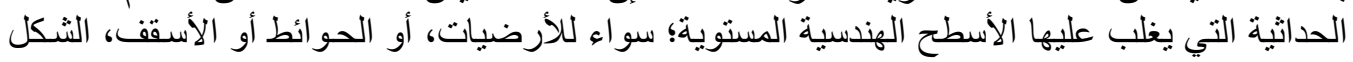
رقم (3). 

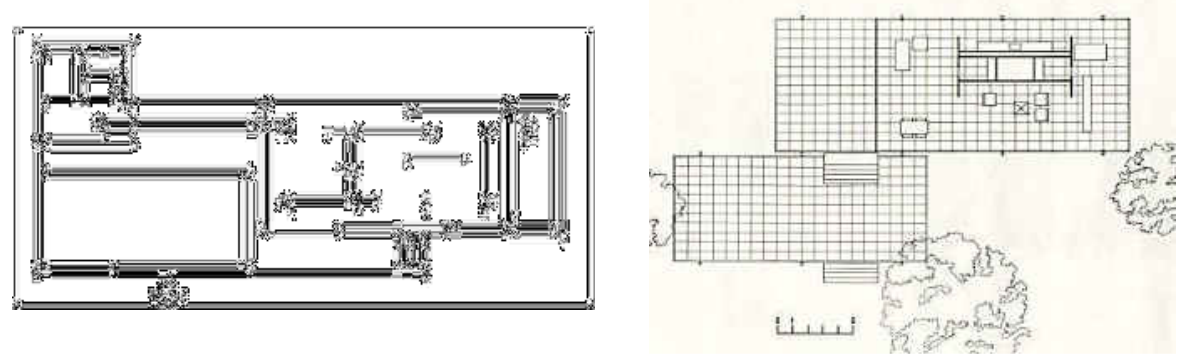

الثكل رقم (1). المسقط الأفقي في أعمال "ميس"(القو اعد الو اضحة في التصميم).

\section{الثكل رقم (2). المسقط الأفقي في أعمال "جيري"(لا نوجد قو اعد واضحة).}

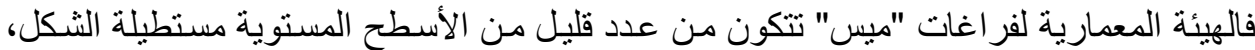

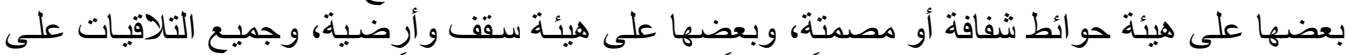

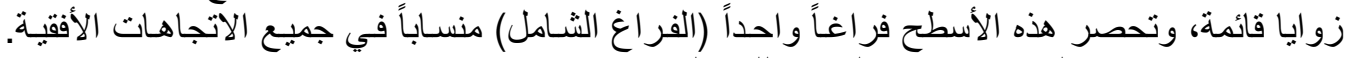

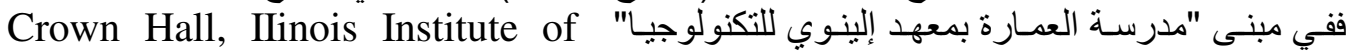
Technology

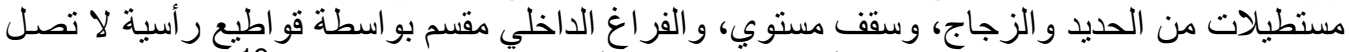

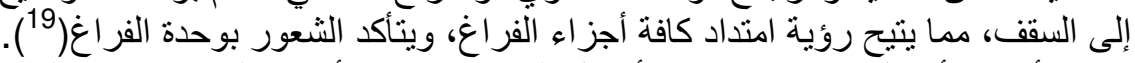

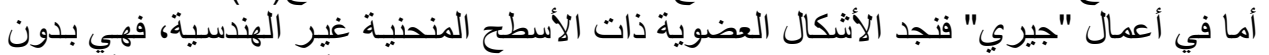

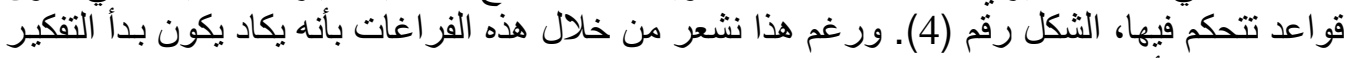

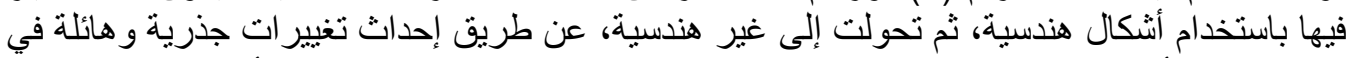

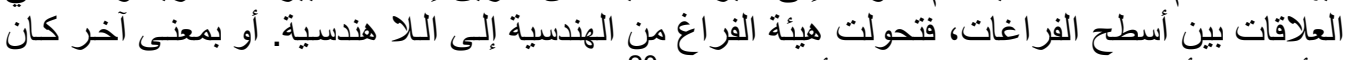

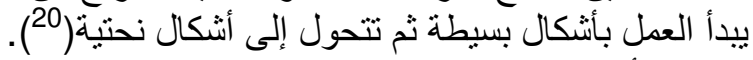

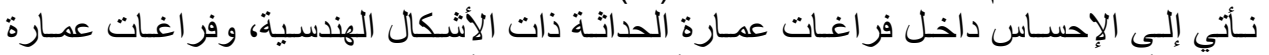

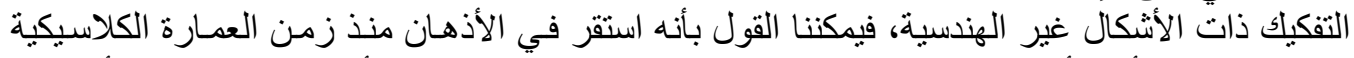

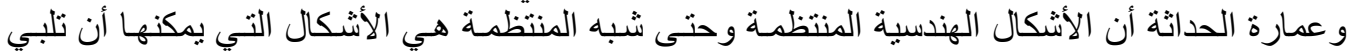

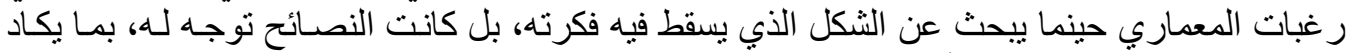

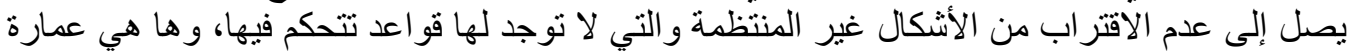




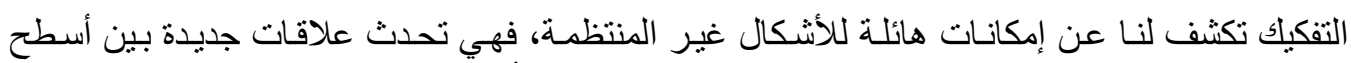

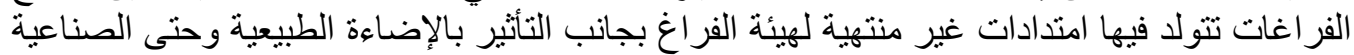

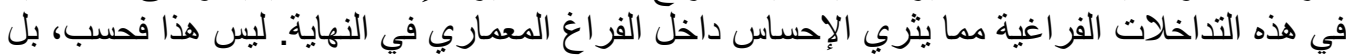

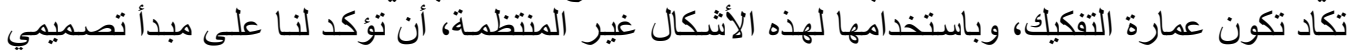

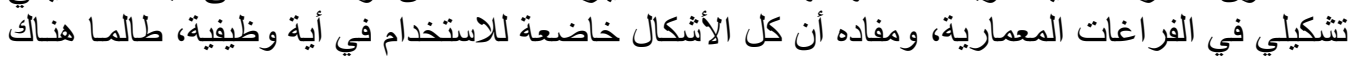

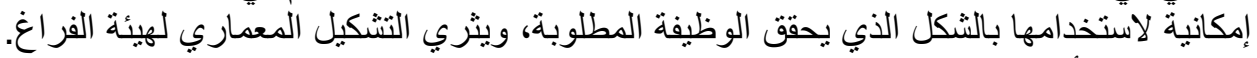

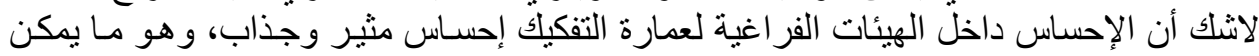

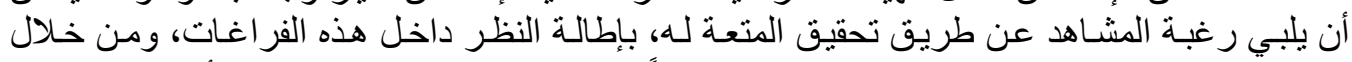

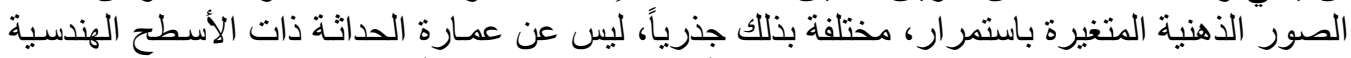

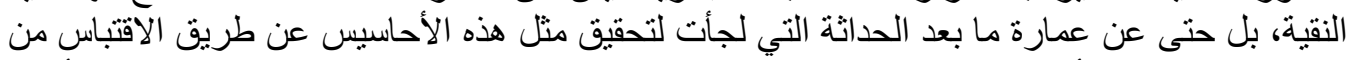

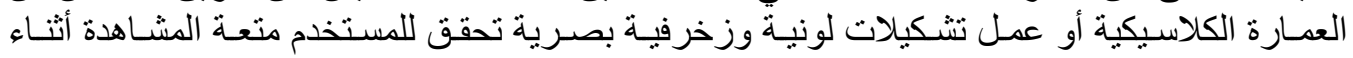

استخدامه للقر اغ.

\section{4-2-2-3 العلاقة بين الداخل والخارج (الهيئة الخارجية): من البساطة إلى التعقيا}

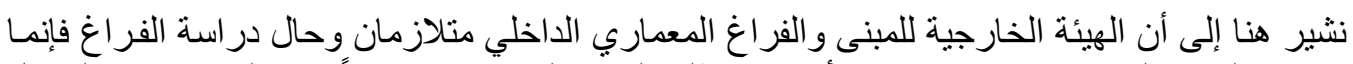

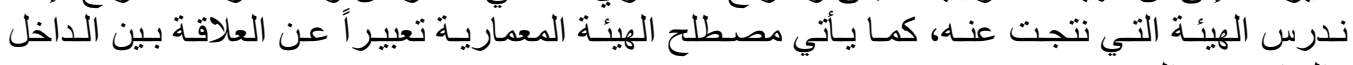

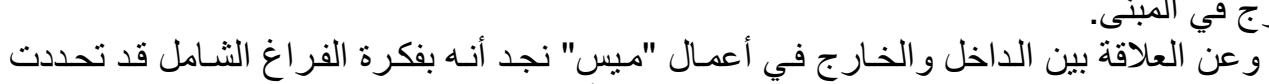

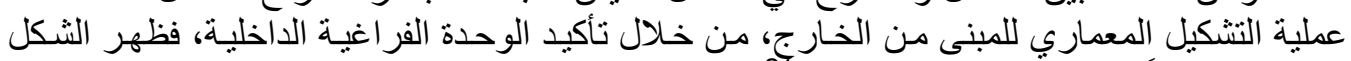

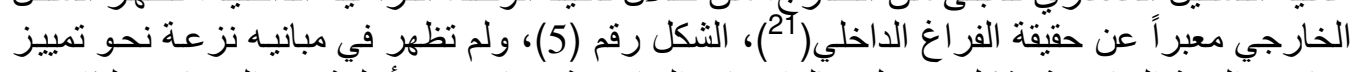

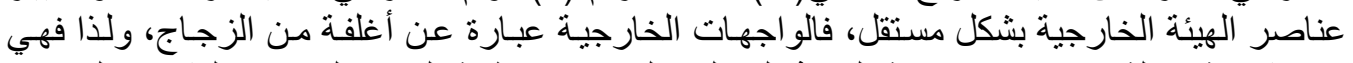

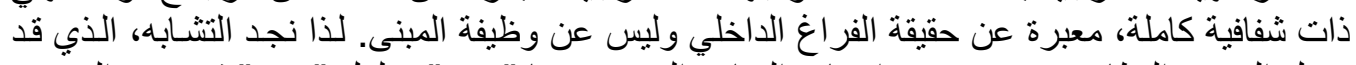

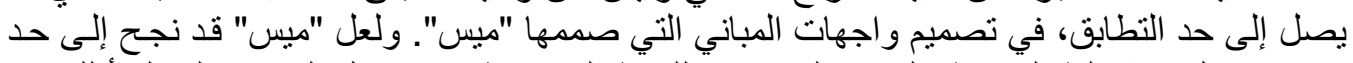

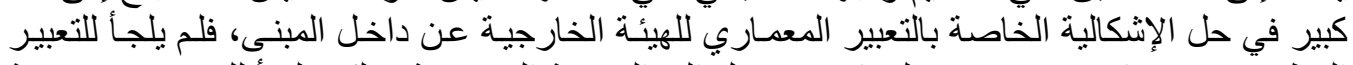

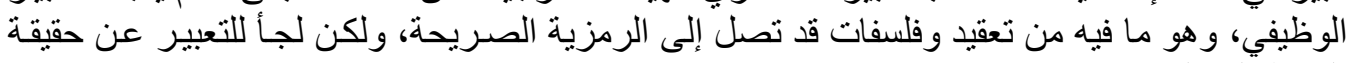

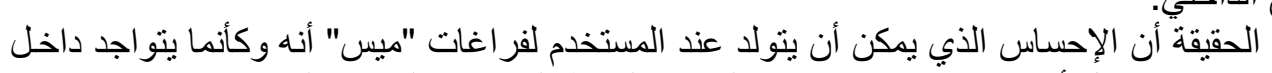

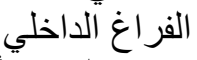

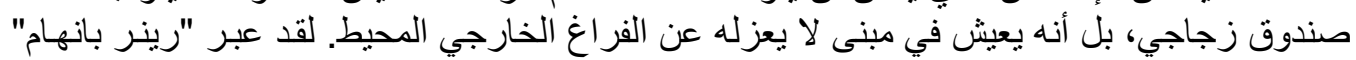
Ryner Banham للاهدوء التأملي"(22). 


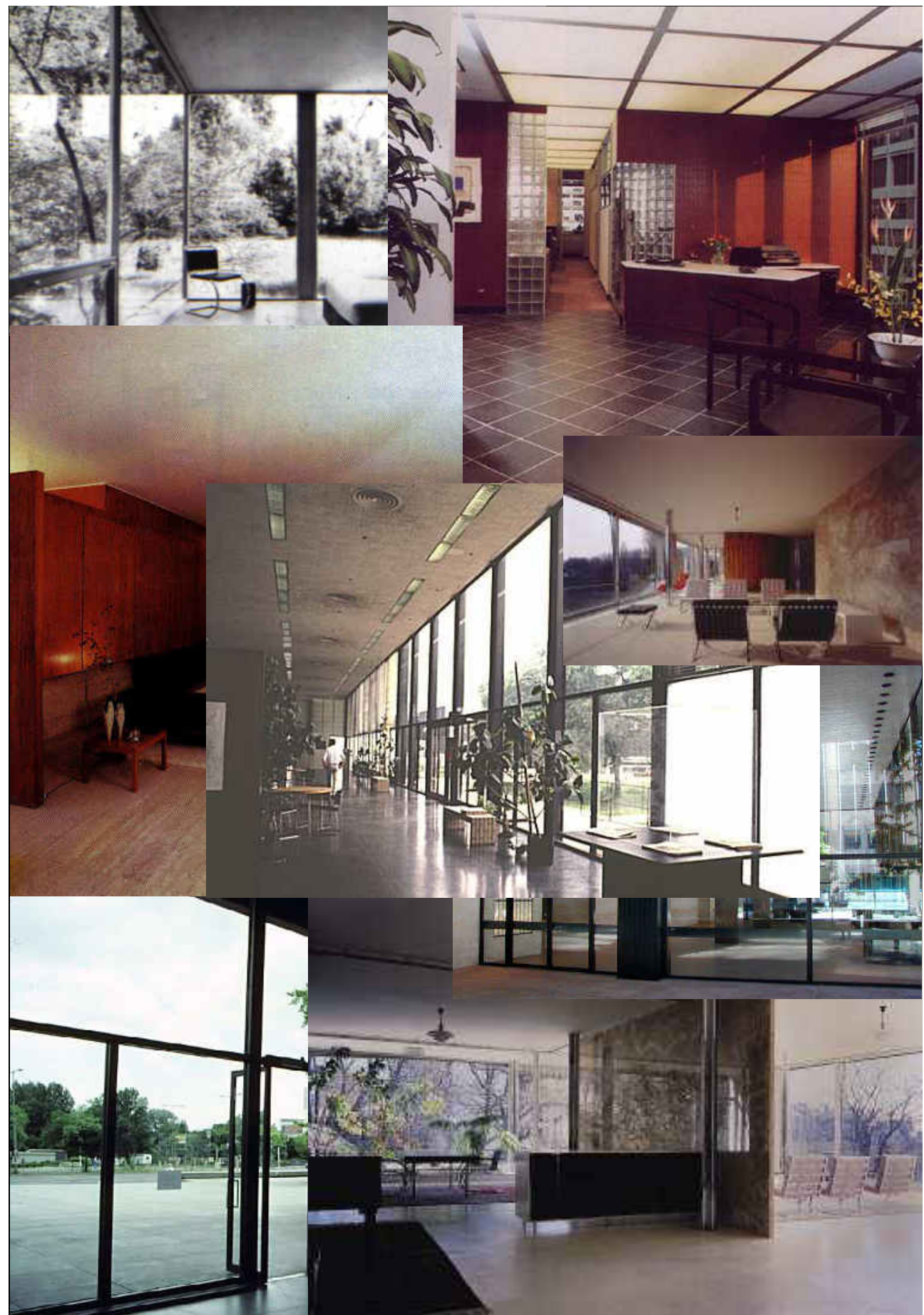

الثكل رقم (3). نماذج لهيئات فر اغية من أعمال "ميس" (هندسية ومحددة الأسطح). 


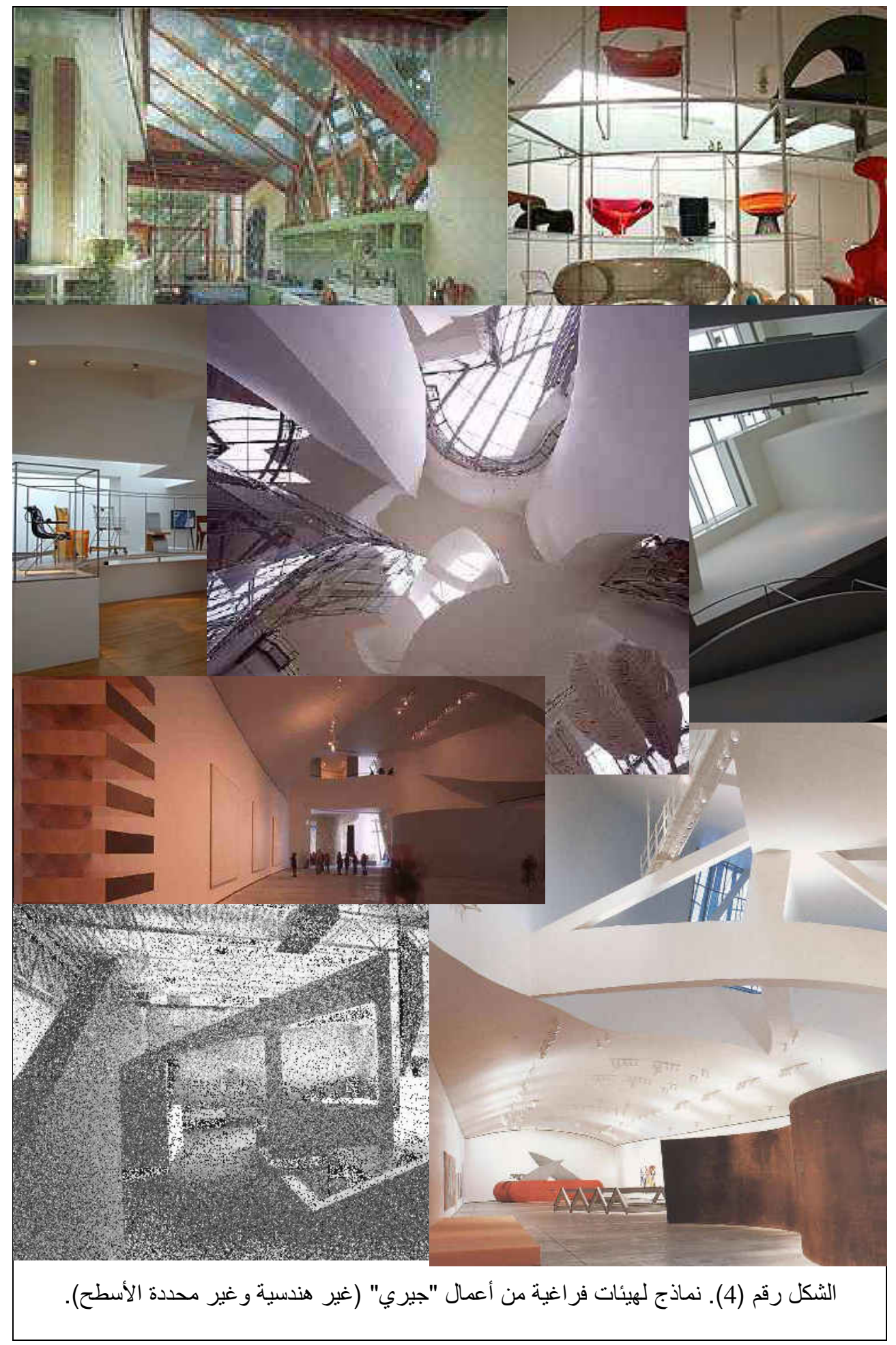




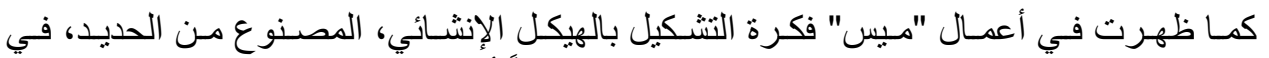

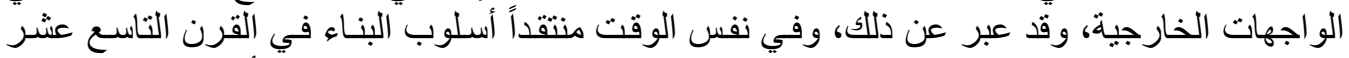

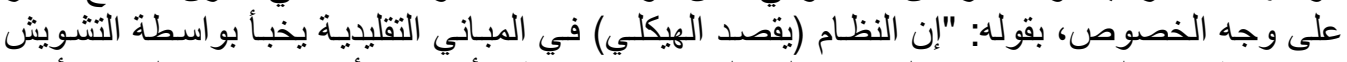

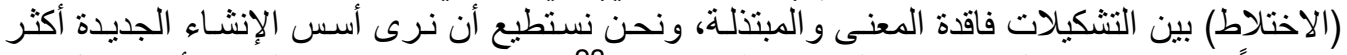

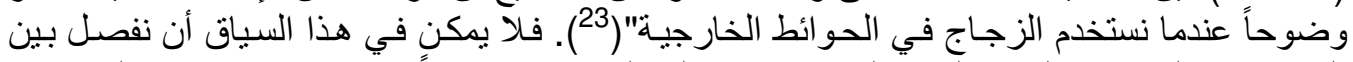

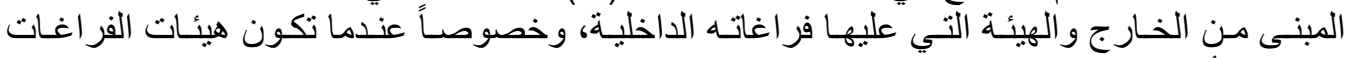

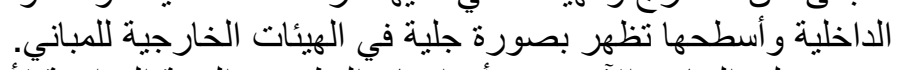

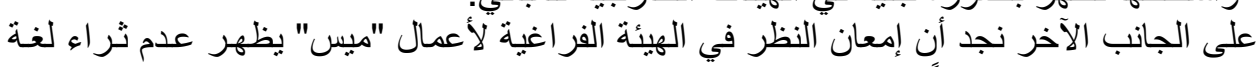

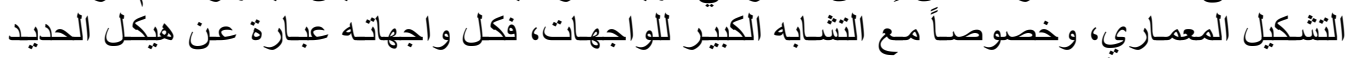

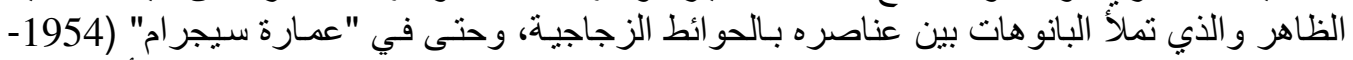

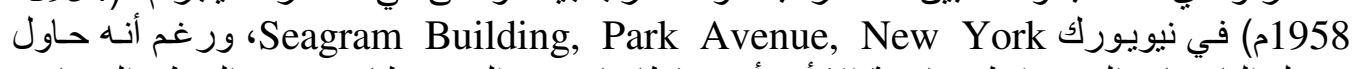
تحويل البانوهات إلى حورئط ستائرية إلا أنه أوجد قطاعات من الحديد ظـاهرة فوق السطح الزجاجي

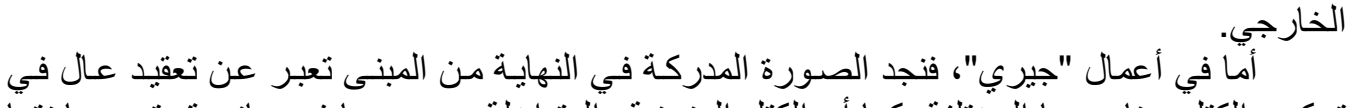

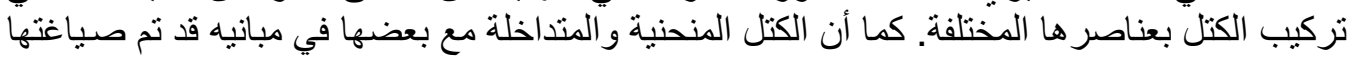

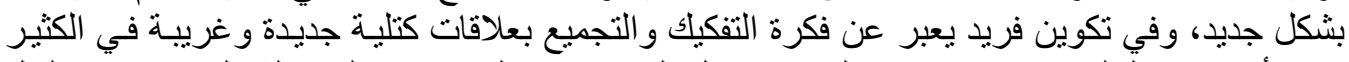

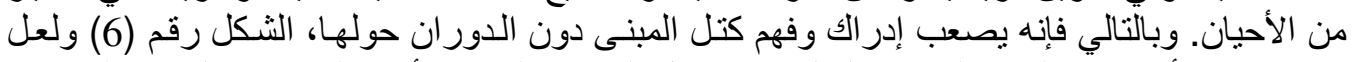
هذا ما يمكن أن يثري النظر إلى هذه الكتل، من خلال المناظ النّر المتغيرة أثناء الحركة حول هذه المباني.

\section{5-2-2-3 بنية الفراغ: من عصر الآلة إلى عصر الثورة الرقمية}

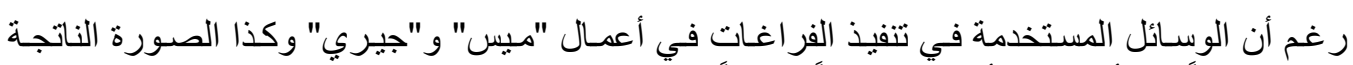

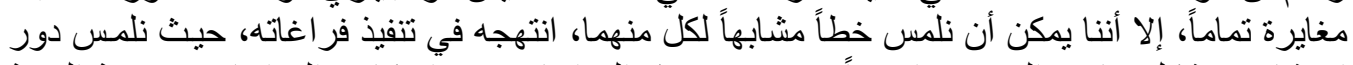

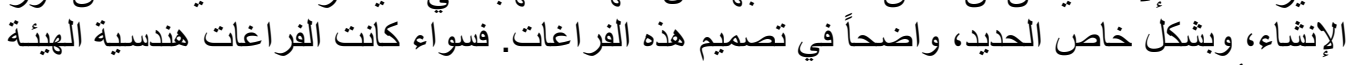

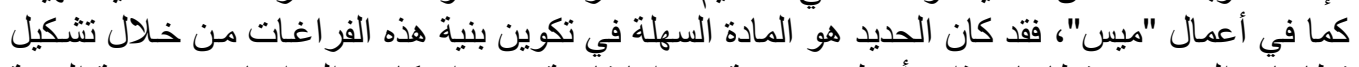

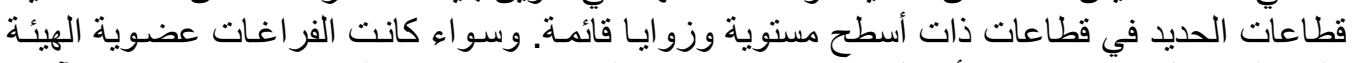

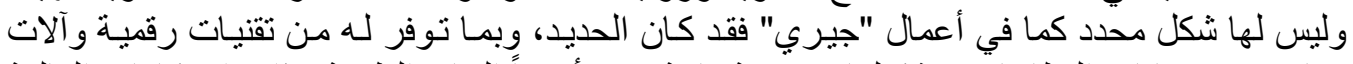

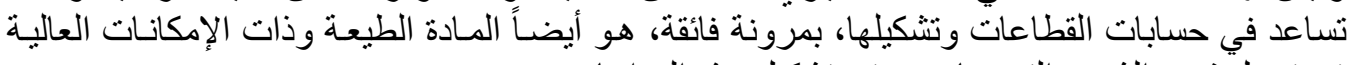

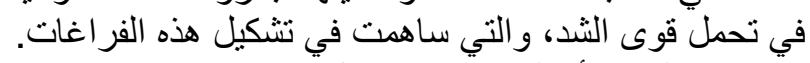

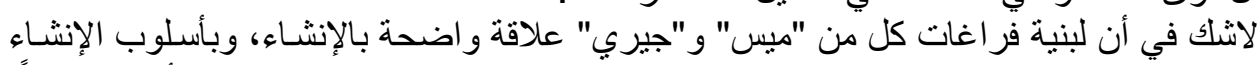

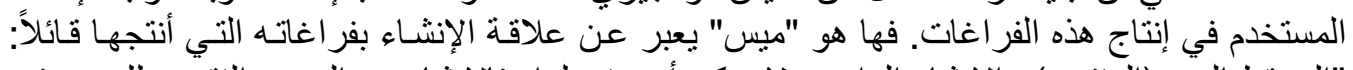

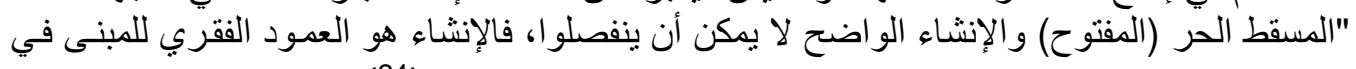

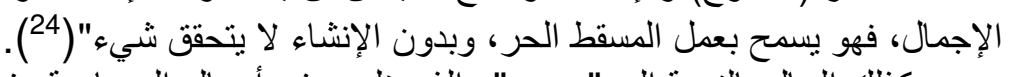

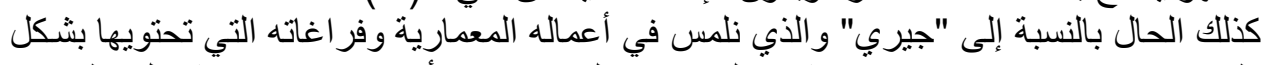

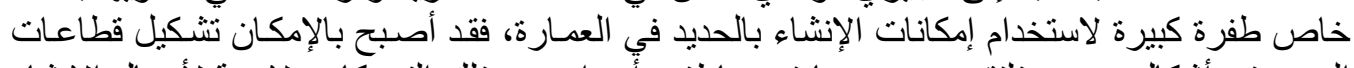

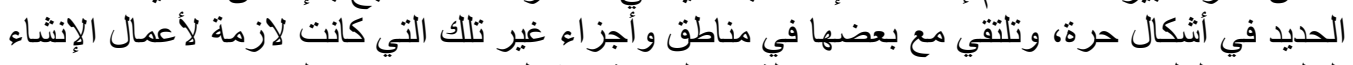

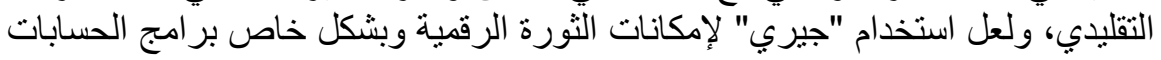

Banham, R. (1975). Age of Masters. $\left({ }^{23}\right)$ Norberg-Schulz C. (1974). Meaning in Western Architecture, p.183 $\left({ }^{24}\right)$ 


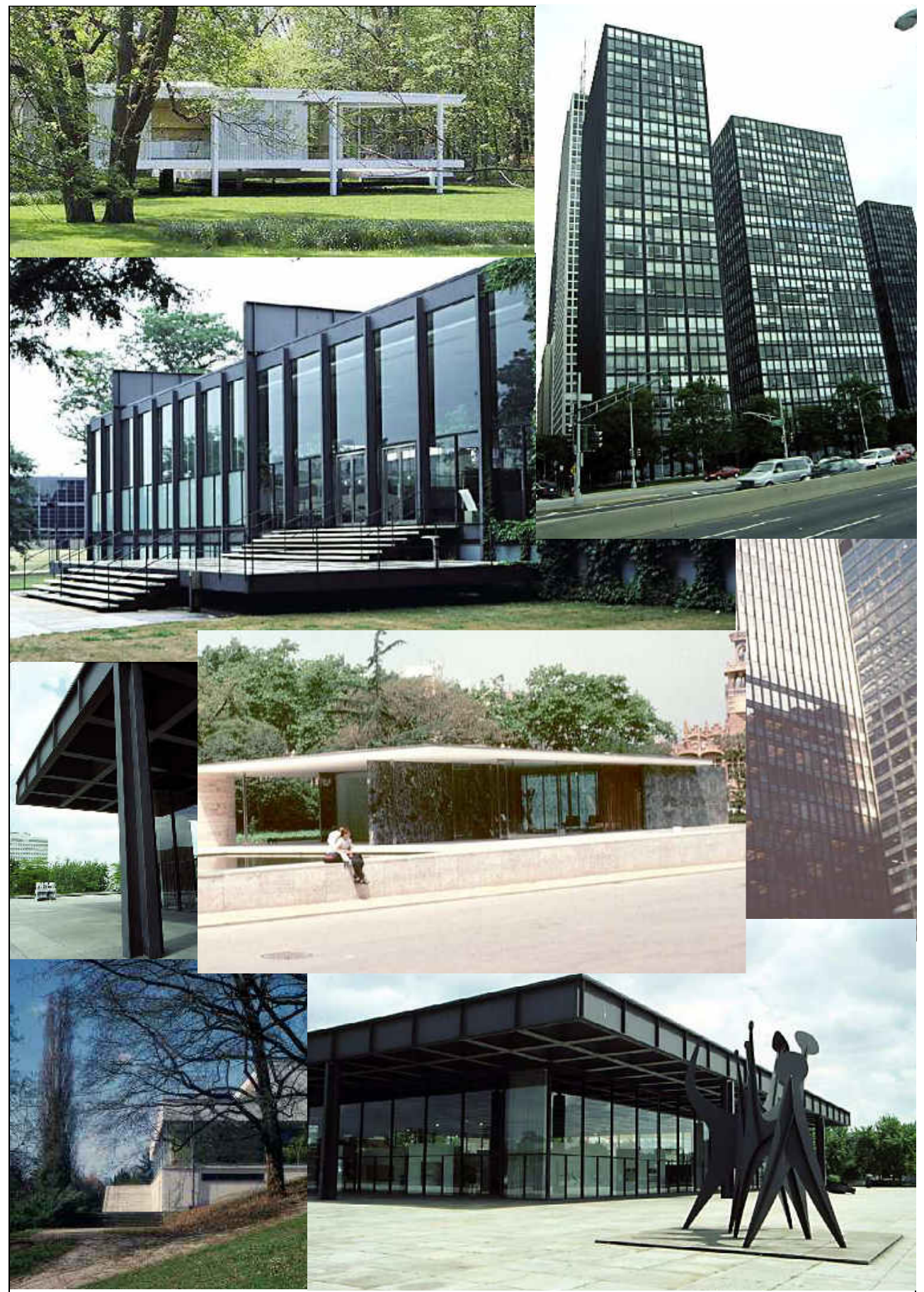

الثكل رقم (5). الهيئة المعمارية الخارجية لفر اغات أعمال "ميس" (البساطة المتتاهية). 


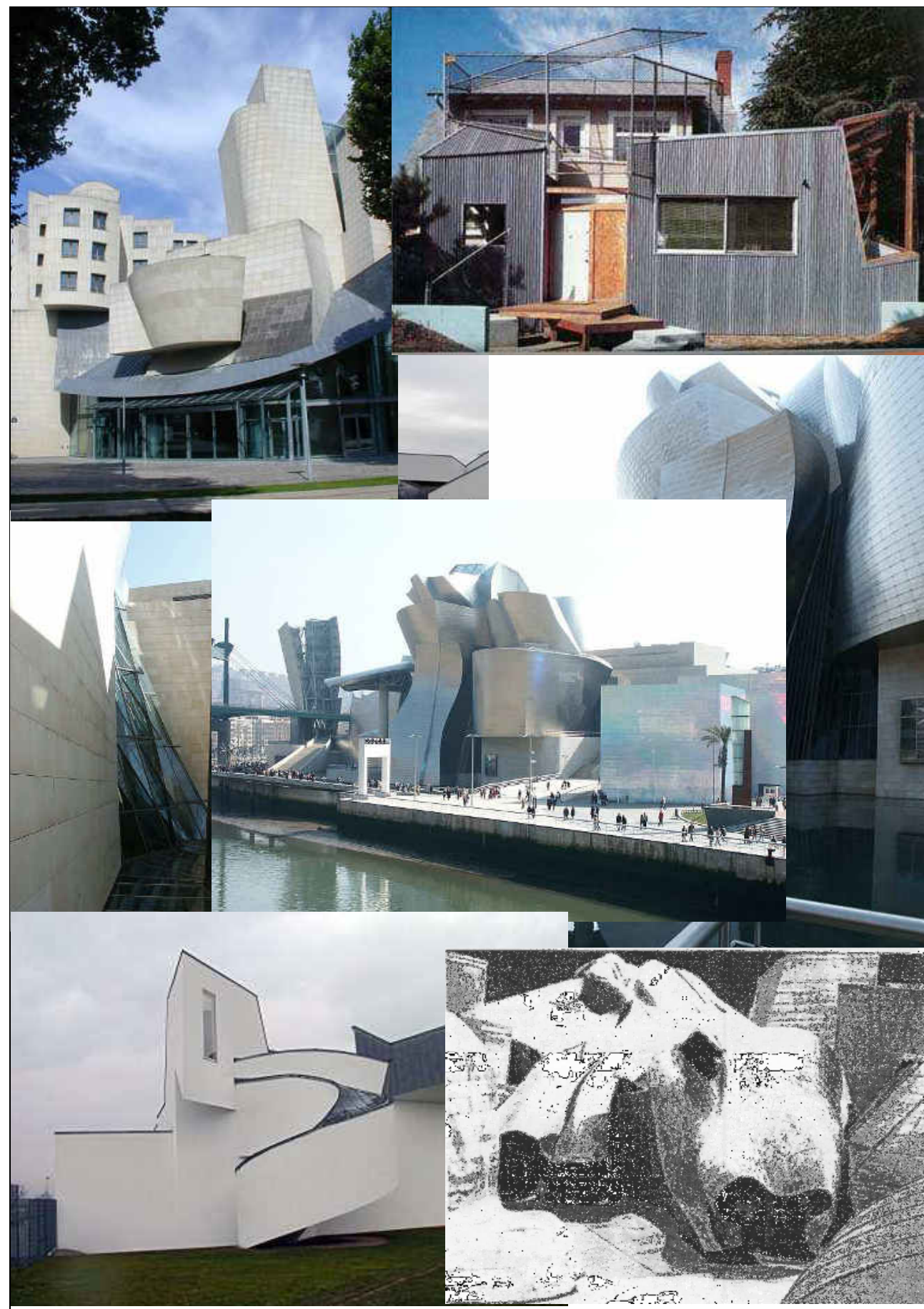

الثكل رقم (6). الهيئة المعمارية الخارجية لفراغات أعمال "جيري" (النعقيد العالي).

و المحاكاة للنماذج، قد ساعده في تحقيق ما كان يهدف إليه من إنتاج هذه الأشكال النحتيـة الغرييـة. ففي

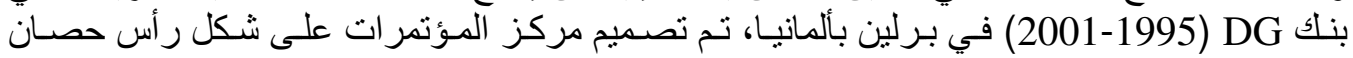


ليكون مغطى بغلاف من الإستانلس ستيل Stainless Steel، و هو من القطع القليلة التي بناها "جيري"

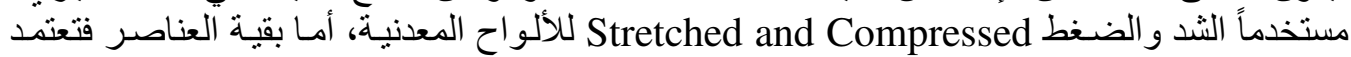

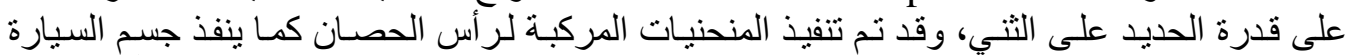

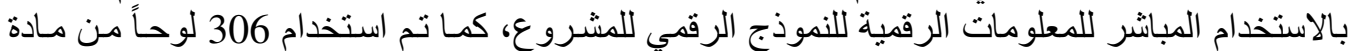
ستايروفوم Computer Numerical Control أو CNC Router بو اسطة جهاز Router و هو جهاز مؤتمت يستخدم المعلومات الرقمية لتشكيل ألواح من مو اد مختلفة، وقد تم تغطية الهيكل في النهاية بألو اح إستانلس ستيل Stainless Steel بسماكة 4 ملليمتر ، تم تجميعها حول مئ الهيكل

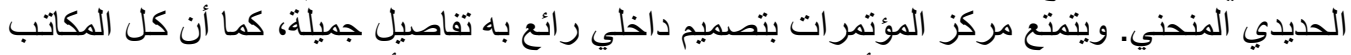

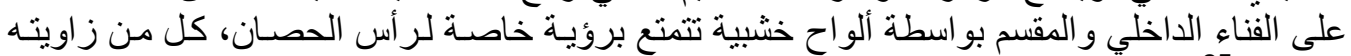

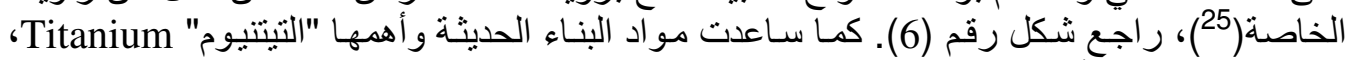

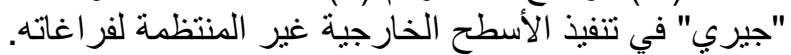

\section{3-3 نتائج دراسة الفراغ المعماري في أعمال ميس وجيري} يوضح الجدول رقم (1). ملخص نتيجة التحليل المقارن لأعمال كل من "ميس فـان درروه" كمعماري

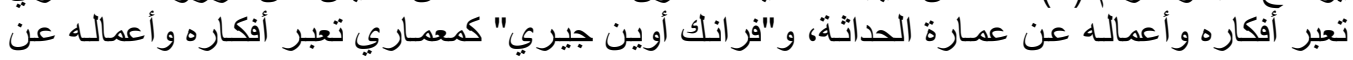
اتجاه عمارة التفكيك.

الجدول رقم (1). ملغص التحليل المقارن بين الفراغ المعماري في أعمال "ميس" و"جيري".

\begin{tabular}{|c|c|c|c|c|c|}
\hline \multicolumn{5}{|c|}{ جوانب تحليل الفراغ المعماري } & \\
\hline بنية الفراغ & هيئة المبنى & هيئة الفراغ & تصميم الفراغ & محددات الفراغ & \\
\hline 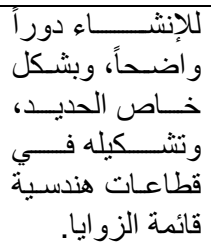 & 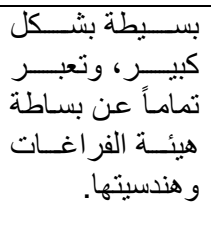 & 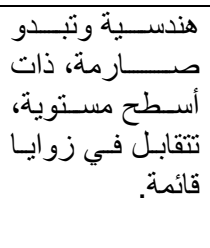 & 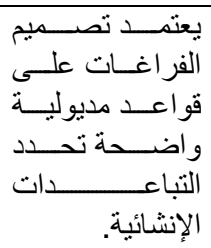 & 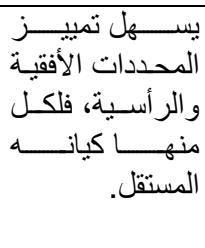 & فيس \\
\hline 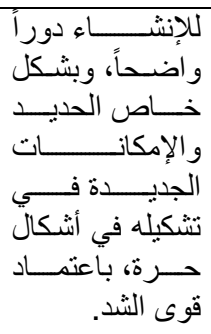 & 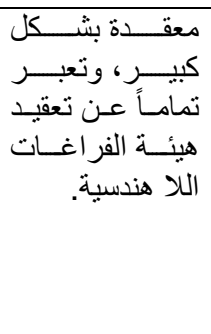 & 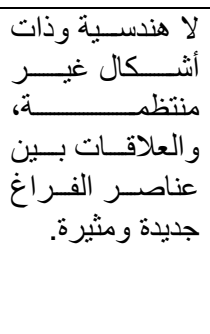 & 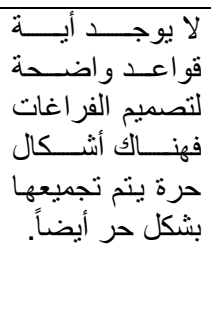 & 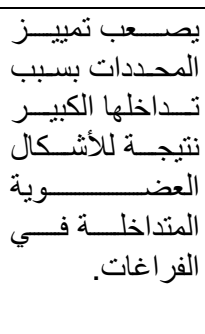 & أعمال \\
\hline
\end{tabular}

5 -5 الخلاصة

مما سبق بمكن استخلاص النقاط التالية:

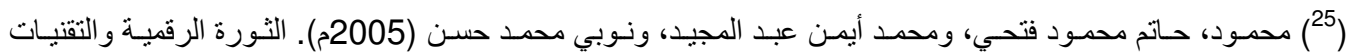
المستخدمة في العمارة - التصميم و التنفيذ. 


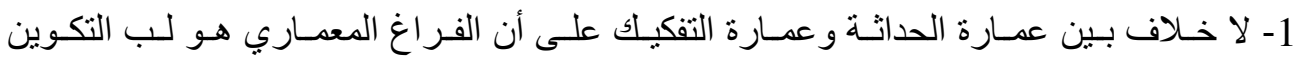

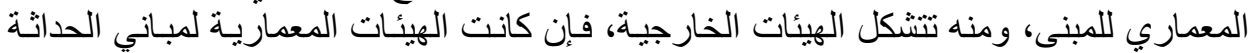

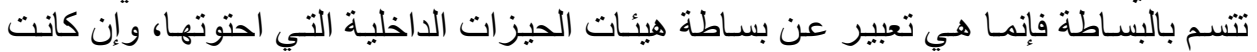

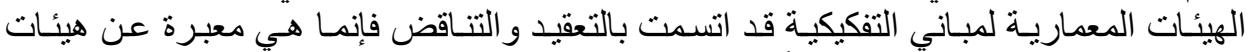
الحيزات الداخلية التي احتوتها أبضاً.

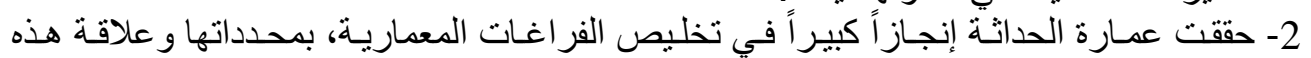

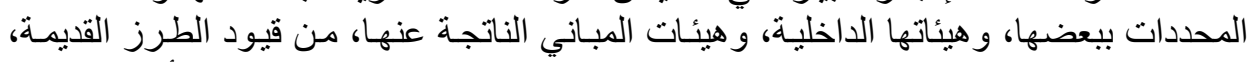

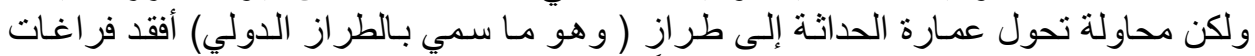

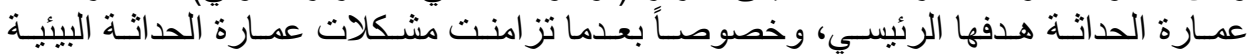

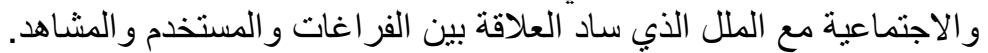

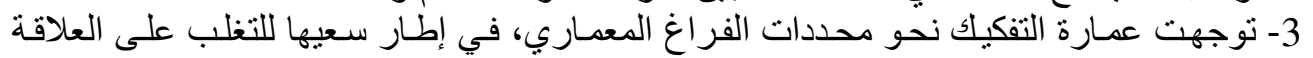

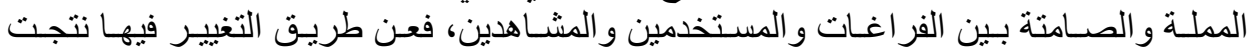

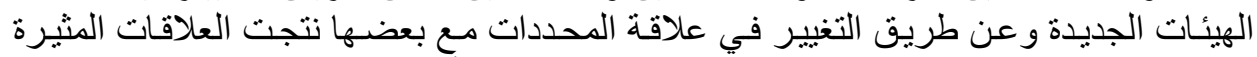

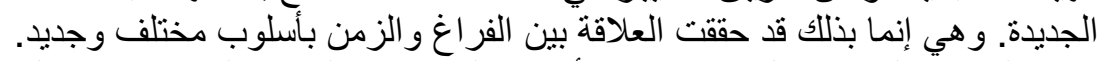

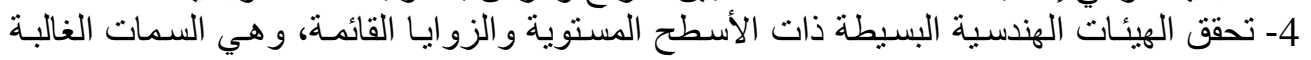

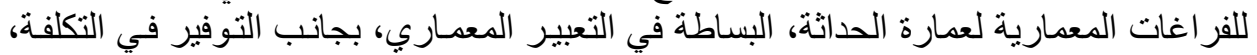

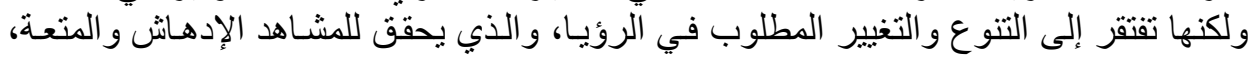

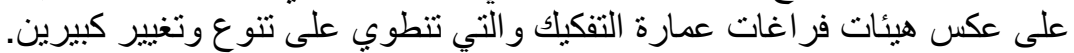

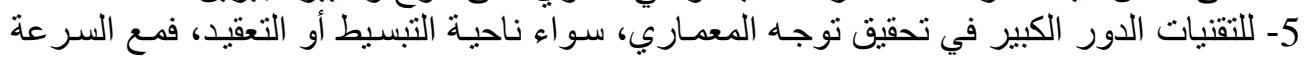

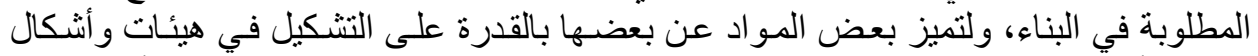

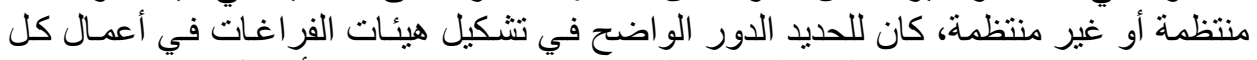

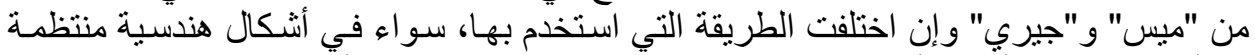

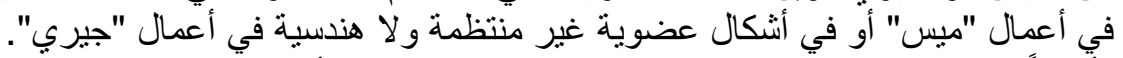

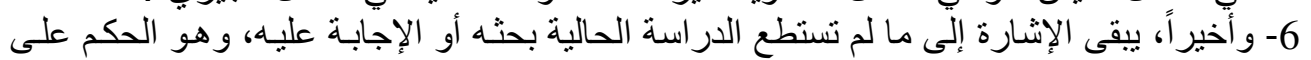

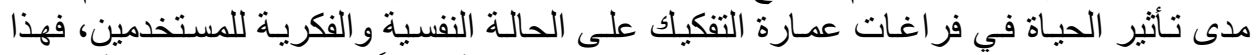

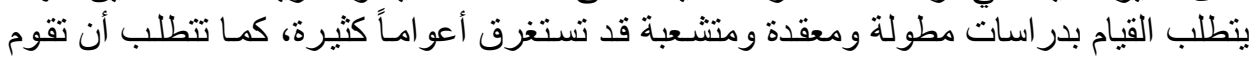

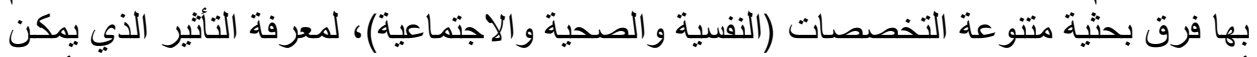

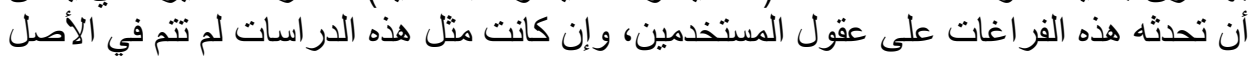

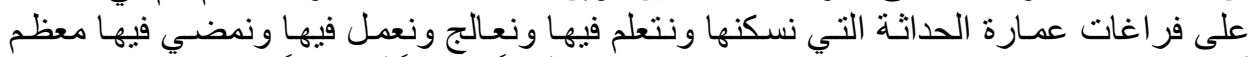

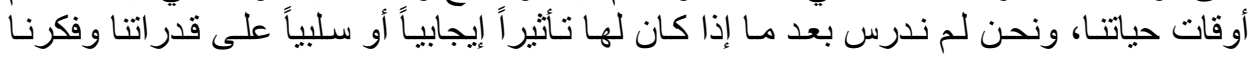

وشخصياتنا.

المراجع

1. أبو دية، نبيل (2002م)، من النهضة إلى الحداثة، تاريخ العمـارة الغربيـة ونظرياتها، الجامعة الأردنية، 2. بلدر، عصام عبده، ومحمد سامي الثافعي (1968م)، مفهوم الفراغ في العمارة، مجلة جمعيـة المهندسين

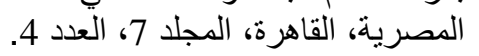

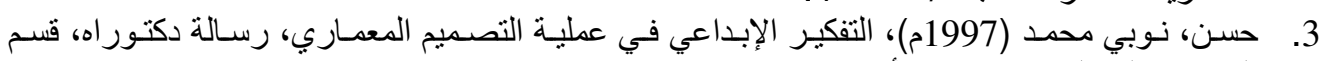

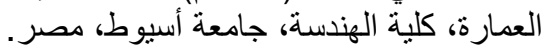

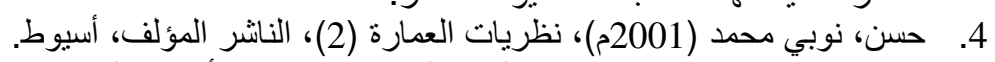

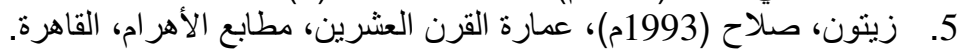
6. 
7. علي، خالد علي يوسف (2001). العمارة المعاصرة و المردود الفكري و التطبيقي على العمـارة المصرية

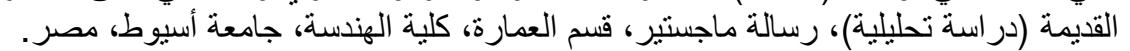

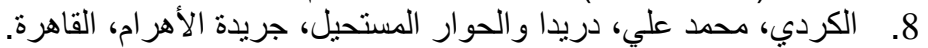

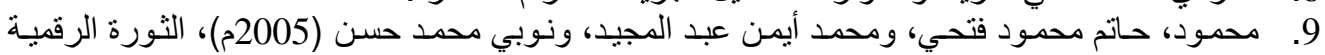

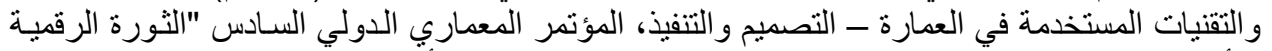

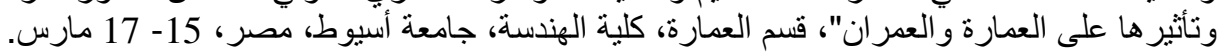

10. Asensio, N. (2004). Great Architects, Atrium Group, Barcelona, Spain.

11. Banham, R. (1975). Age of Masters, The Architectural Press, London.

12. Ching, F. D. K.(1974). Architecture: Form, Space \& Order, Van Nostrand Company, Inc., New York

13. Giedion, S.(1967). Space, Time and Architecture, Cambridge, Massachustts Harvard University Press.

14. Kaufmann, E. \& Ben Raeburn. (1960). Frank Lloyd Wright, Writings \& Buildings, Horizon Press, INC, U.S.A.

15. Norberg-Schulz C.(1974). Meaning in Western Architecture, Studio Vista, London.

$$
\text { الصور الواردة في هذا البحث مأخوذة من المراجع و المواقع التالية: }
$$

16. http://members.aol.com/richpat/860/Picnew.htm

17. http://www.bc.edu/bc_org/avp/cas/fnart/fa267/mies.html

18. http://www.bluffton.edu/ sullivanm/iit/iit.html

19. http://www.bluffton.edu/ sullivanm/spain/barcelona/mies/pavilion.html

20. http://www.bluffton.edu/ sullivanm/spain/bilbao/gehryguggenheim/guggenheim index.html

21. http://www.cc.columbia.edu/cu/gsapp/BT/GATEWAY/FARNSWTH/images.html

22. http://www.greatbuildings.com/buildings/Guggenheim_Bilbao.html

23. http://www.lostandfoundproductions.org/glass.html

24. http://www.miesbcn.com/Pabelloneng01.htm

25. http://www.vitruvio.ch/arc/contemporary/1946-2000/americancenter.htm

26. http://www.vitruvio.ch/arc/contemporary/1946-2000/seagrambuilding.html

27. http://www.vitruvio.ch/arc/contemporary/1946-2000/vitradesignmuseum.htm

28. http://www.volny.cz/tugendhat/

29. Saggio, A. (2001). Digital Gehry: Material Resistance / Digital Construct, Birkhauser. 